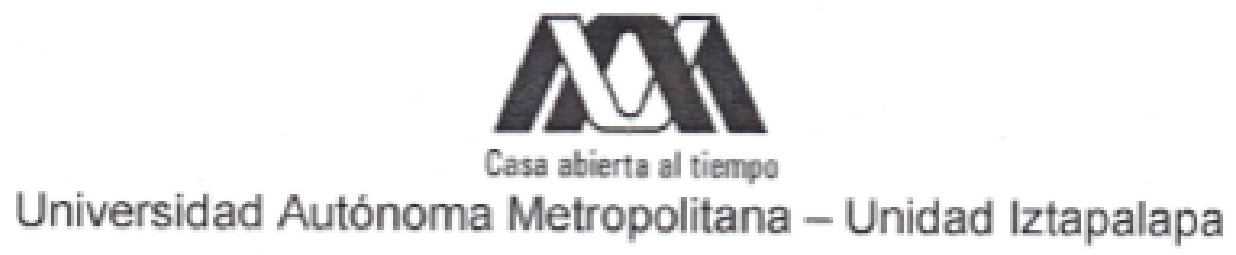

División de Ciencias Básicas e Ingenieria

\title{
Estudio de acceso al espectro satelital utilizando funciones de radios cognitivos
}

Idónea Comunicación de Resultados para obtener el grado de Maestra en Ciencias y Tecnologías de la Información

\author{
por \\ Kenia Salazar Cruz \\ 2153805284 \\ Dr. Michael Pascoe Chalke
}

Asesores: Dr. Enrique Rodriguez de la Colina

Jurado calificador :

Presidente:

Dr. Jorge Carlos Mex Perera

Secretario:

Dr. Miguel Ángel Ruiz Sánchez

Vocal:

Dr. Michael Pascoe Chalke

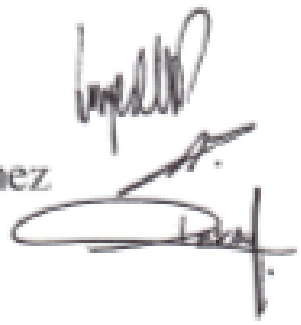

Ciudad de México, Febrero 2018 


\section{Agradecimientos}

Agradezco a Dios por ponerme en este camino, acompañarme a cada paso que doy.

Agradezco a mis padres y hermanas por acompañarme en cada decisión que he tomado en la vida, por acompañarme en mis desvelos, momentos difíciles y por mostrarme siempre su apoyo, comprensión y amor.

También, agradezco a mis profesores del posgrado en Ciencias y Tecnologías de la Información por su apoyo y comprensión.

Asimismo, agradezco a mis asesores y sinodales por sus comentarios y apoyo durante el proceso de investigación y redacción de este documento.

Quiero agradecer al Consejo Nacional de Ciencia y Tecnología por el apoyo económico brindado durante mis estudios de maestría.

Por último, y no por eso menos importante, agradezco a mis amigos, aquellos que me acompañaron en esta gran aventura, sin su ayuda, consejos y motivación no habría llegado a cumplir con esta meta. 


\section{Resumen}

En este trabajo se propone el uso de un sistema de control denominado "gestor" que administra recursos para un sistema que funciona por multicanalización por división de tiempo y por demanda para el acceso (TDMA/DAMA) cuando no existen solicitudes extraordinarias por parte de los usuarios primarios. Se presenta un algoritmo para usar principios de funcionamiento utilizados en Radios Cognitivos para un sistema satelital cuando existe una solicitud extraordinaria de acceso al medio por parte de usuarios primarios.

Se presentan los resultados de simulaciones hechas con el programa NS-2 los cuales presentan escenarios donde conviven usuarios primarios y secundarios. Estas pruebas se realizaron con diferentes escenarios variando la cantidad de usuarios primarios y secundarios en cada prueba, pensando en demostrar la parte TDMA/DAMA del "gestor". Uno de los escenarios está formado por un satélite geoestacionario, dos estaciones primarias (una estación transmisora y una receptora) y dos estaciones secundarias (una estación transmisora y una receptora). Otro escenario considera varias estaciones primarias y secundarias tanto transmisoras como receptoras.

Las simulaciones se realizaron sustentando el trabajo en la investigación del estudio de la ocupación satelital, basada en investigaciones de diferentes empresas operadoras de servicios satelitales, por ejemplo, Hispasat, Eutelsat y la Sociedad Europea de Satélites. Con base en este estudio, se puede concluir que existen frecuencias que no 
están siendo utilizadas todo el tiempo, tal como pasa en las comunicaciones terrestres, las comunicaciones satelitales también se ven afectadas por este fenómeno. 


\section{CONTENIDO}

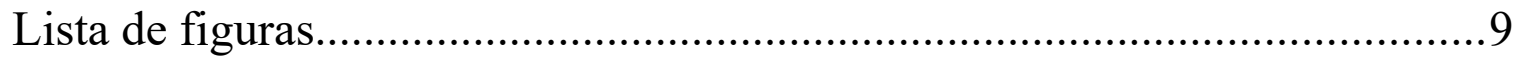

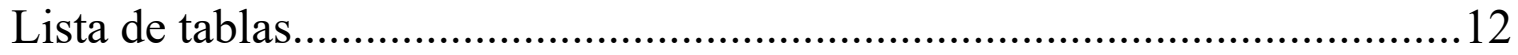

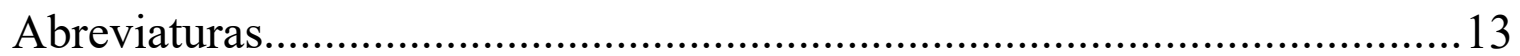

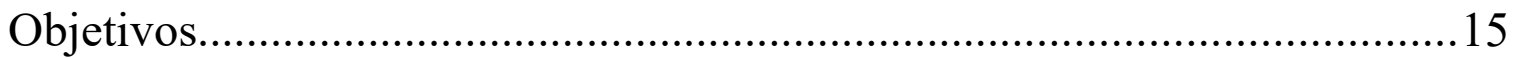

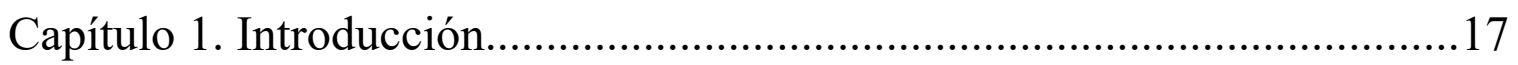

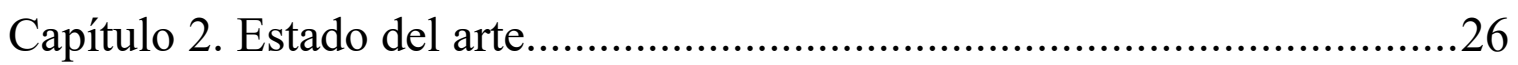

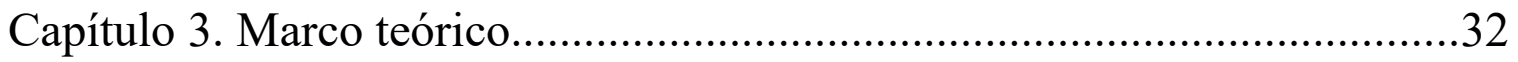

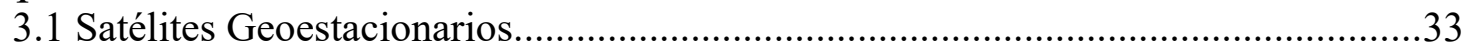

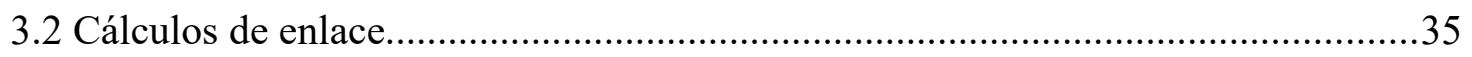

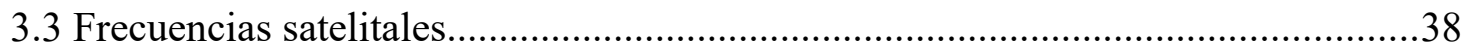

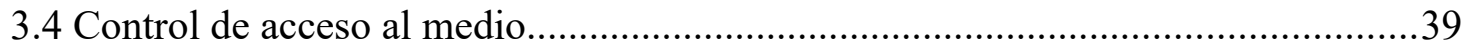

Capítulo 4. Entorno de simulación...........................................................43

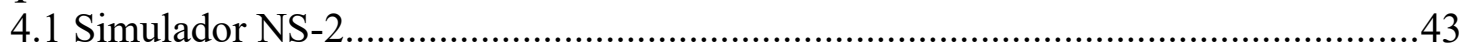

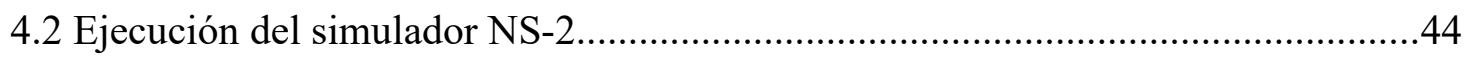

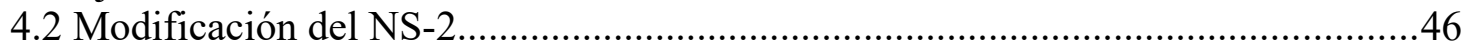

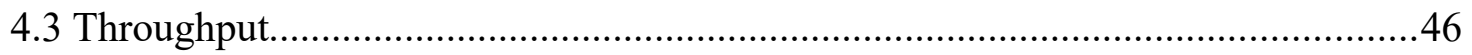

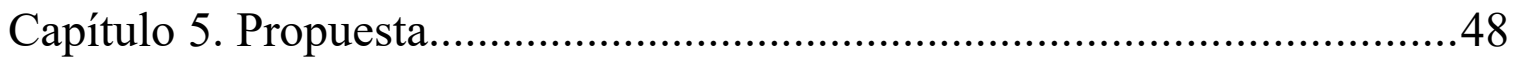

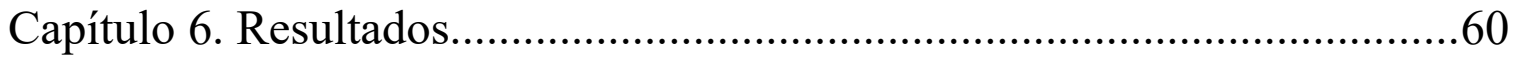

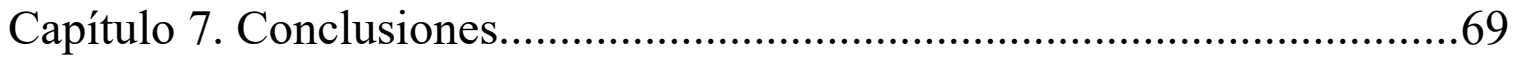

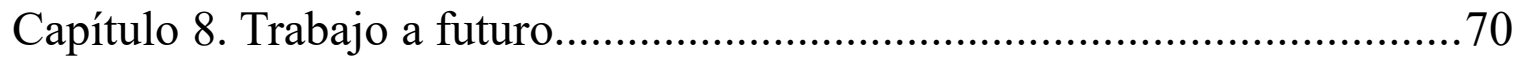

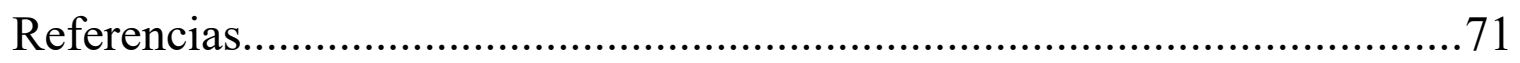

ANEXO A. Script de Throughput en Perl.................................................75

ANEXO B. Programa para la simulación de US y UP en NS-2 ..................77 


\section{Lista de figuras}

Figura 1. Distribución de utilización HISPASAT en $30^{\circ}$ Oeste........................... 19

Figura 2. Utilización de capacidad: a) Hispasat $61^{\circ} \mathrm{O}$, b) capacidad de la SES.............19

Figura 3. Asignación de 24 transpondedores dentro del satélite [9]......................21

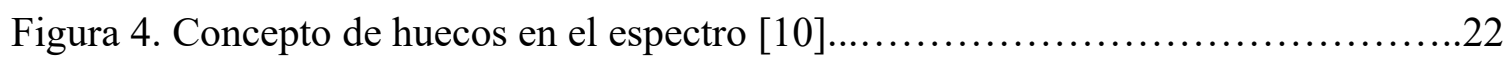

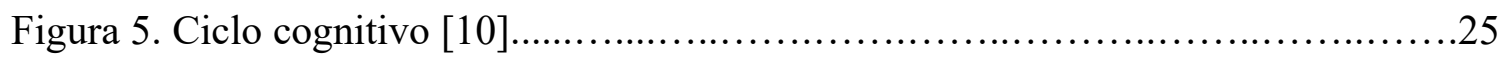

Figura 6. Escenario de una red satelital cognitiva propuesta en $[25] \ldots \ldots \ldots \ldots \ldots \ldots \ldots . \ldots 30$

Figura 7. a) Escenarios propuestos en [26], [28], [30], [33]-[37], b) Escenario propuesto en [29]. En donde: I - enlace perteneciente, C - enlace cognitivo.................................. 31

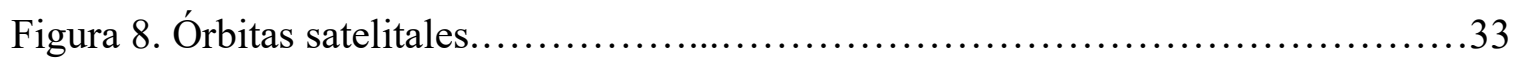

Figura 9. Comunicación satelital.....................................................

Figura 10. Comunicación utilizando un control de acceso al medio FDMA............... 40

Figura 11. Comunicación utilizando un control de acceso al medio TDMA...............41

Figura 12. Comunicación utilizando un control de acceso al medio CDMA................41

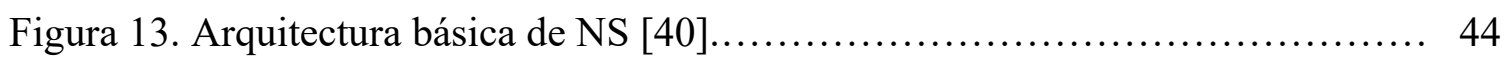

Figura 14. Ejemplo de throughput vs tiempo, usuarios primarios y secundarios.........47

Figura 15. Primer escenario propuesto con dos estaciones secundarias y dos estaciones

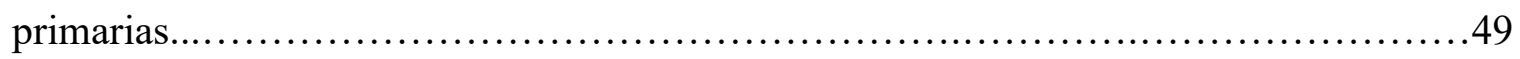

Figura 16. Envío de información del UP-1 al gestor..................................50 
Figura 17. Estaciones secundarias escuchando broadcast, y US-1 pidiendo reservación y asignación de espacio...................................................... 52

Figura 18. US-4 en espera de reservación...................................54

Figura 19. Diagrama de flujo de algoritmo para reservación......................55

Figura 20. Asignación de espacio a UP en espacios reservados por US...................56

Figura 21. a) Solicitud de reserva de un UP cuando todos los transpondedores están asignados, b) Asignación de ranura a UP quitando a US............................57

Figura 22. Throughput medido en la estación receptora del UP haciendo uso del $72 \%$ del transpondedor........................................................... 60

Figura 23. Throughput medido en la estación receptora del UP y del US haciendo uso del $72 \%$ del transpondedor por parte del UP......................................61

Figura 24. Throughput medido en las estaciones receptoras de los 5 UP y 10 US, se hace uso del $12 \%$ del transpondedor por parte de los UP, paquetes de 500 bytes............62 Figura 25. Número máximo de usuarios secundarios para las diferentes ocupaciones con

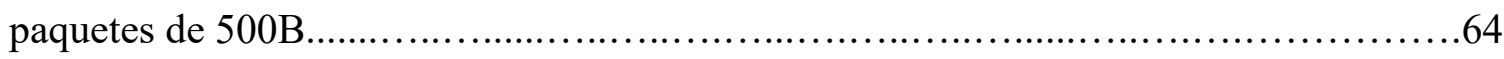

Figura 26. Número máximo de usuarios secundarios para las diferentes ocupaciones con

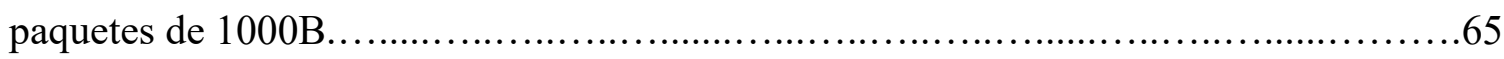

Figura 27. Número máximo de usuarios secundarios para las diferentes ocupaciones con

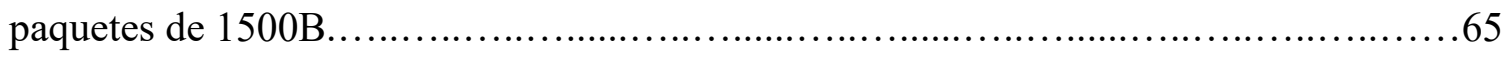


Figura 28. Porcentaje de ocupación para diferentes número de US, variando el tamaño de

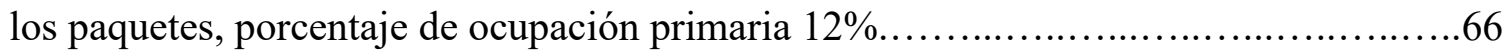

Figura 29. Porcentaje de ocupación para diferentes número de US, variando el tamaño de

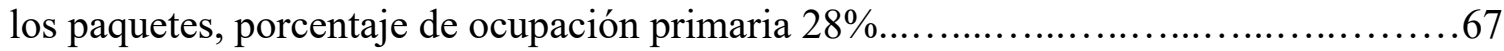

Figura 30. Porcentaje de ocupación para diferentes número de US, variando el tamaño de

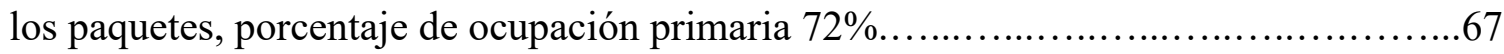




\section{Lista de tablas}

Tabla 1. Ocupación satelital de EUTELSAT, 2015-2016 [6]............................ 18

Tabla 2. Bandas de frecuencias para comunicaciones satelitales [39]...................39

Tabla 3. Fragmento de traza de la simulación...................................45

Tabla 4. Significado de los caracteres en la traza para la columna $1 \ldots \ldots \ldots \ldots \ldots \ldots \ldots . . . \ldots 45$

Tabla 5. Contenido de cada columna en la traza de salida de la simulación..............45

Tabla 6. Características del enlace satelital para la simulación........................59

Tabla 7. Resultados de las simulaciones variando UP, US, ocupación y tamaño de los

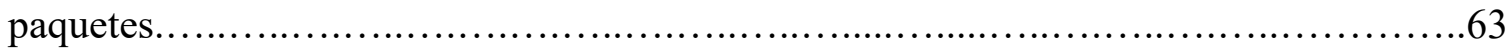




\begin{tabular}{ll} 
Abreviaturas & \multicolumn{1}{c}{ Significado } \\
CBR & Taza de Bits Constantes \\
CDMA & Acceso múltiple por división de códigos \\
CORDIC & Computadora digital de rotación de coordenadas \\
DAMA & Acceso múltiple asignado bajo demanda \\
DCT & Transformada Coseno Discreta \\
DSA & Acceso dinámico del espectro \\
FAMA & Acceso múltiple con asignación fija \\
FDMA & Acceso múltiple por división de frecuencia \\
FFT & Transformada rápida de Fourier \\
FSS & Servicio satelital fijo \\
GEO & Órbita terrestre geoestacionaria \\
LEO & Órbita terrestre baja \\
MEO & Órbita terrestre media \\
NOC & Centro de control \\
OBP & Procesador a bordo \\
PIRE & Potencia Isotrópica Radiada Efectiva \\
RC & Radio cognitivo \\
RTT & Comunicaciones satelitales \\
SatCom & Tiempo ida y vuelta \\
\hline
\end{tabular}


Abreviaturas

SDR

SES

TDMA

TP

UP

US

\section{Significado}

Radio definido por software

Sociedad Europea de Satélites

Acceso múltiple por división de tiempo

Transpondedor

Usuario Primario

Usuario Secundario 


\section{Objetivos}

Objetivo general:

Diseñar y explorar técnicas de acceso al espectro para sistemas satelitales, utilizando características de redes con radios cognitivos.

Objetivos específicos:

- Estudiar el acceso al medio en comunicaciones satelitales utilizando técnicas de radio cognitivo.

- Estudiar protocolos para redes de radios cognitivas en sistemas satelitales con un enfoque multicapa.

- Diseñar una metodología para la medición del desempeño en el espectro satelital para técnicas de acceso TDMA/DAMA combinado con funciones cognitivas para casos especiales . 


\section{Capítulo 1. Introducción}

Con el paso del tiempo, el espectro radioeléctrico se ha visto con una mayor demanda ya que las comunicaciones inalámbricas han aumentado en los últimos años. Existen ciertos canales o bandas de frecuencias que ya han sido asignadas para diferentes servicios, por ejemplo, televisión, radio y telefonía celular, por ende, los recursos de frecuencias libres son escasos; sin embargo, estudios han demostrado que la utilización de ciertas bandas de frecuencia; por ejemplo, la banda de frecuencias de $50 \mathrm{MHz}$ a $700 \mathrm{MHz}$, sólo es utilizada el 10\% del tiempo [1].

A las comunicaciones satelitales (SatComs, por sus siglas en inglés) les son asignadas ciertas bandas de frecuencias, a las cuales se les identifica por bandas denotadas con letras, tales como la banda $\mathrm{C}$, banda $\mathrm{Ku}$, banda $\mathrm{Ka}$, entre otras. Al contar sólo con ciertas bandas de frecuencia para cubrir los requerimientos de las SatComs, éstas se encuentran saturadas, sin embargo, se tienen frecuencias que no son utilizadas todo el tiempo al igual que en las comunicaciones terrestres [2]. En dichas bandas se cuenta con planes para la distribución de frecuencias para distintos servicios, por ejemplo, de acuerdo al informe anual del año 2010 que presentó HISPASAT [3], las distribuciones quedaron como se muestra en la Figura 1. En donde el 1\% de la utilización del satélite ' $30^{\circ}$ Oeste' corresponde a servicios ocasionales, es decir, al menos el $1 \%$ de la capacidad del satélite no es utilizada todo el tiempo.

En 2014 HISPASAT [4], menciona que para los satélites Amazonas 2, Amazonas 
3 y Amazonas $4 \mathrm{~A}$, ubicados en ' $61^{\circ}$ Oeste', la asignación media anual de capacidad empleada por servicios permanentes en su sistema es del $88.8 \%$, correspondiente a la diferencia de la capacidad total del sistema menos la empleada para usos ocasionales y la no asignada.

Un año después, la Sociedad Europea de Satélites (SES) publicó que en su flota se encuentran 53 satélites geoestacionarios, un total de 1502 transpondedores disponibles de los cuales 1086 son utilizados; es decir, el $27.7 \%$ del total de transpondedores no son utilizados [5], observe la Figura 2 (b).

En 2016, EUTELSAT reportó en su informe anual el porcentaje de ocupación que se puede observar en la Tabla 1.

Tabla 1. Ocupación satelital de EUTELSAT, 2015-2016 [6].

\begin{tabular}{|c|c|c|c|}
\hline Transpondedores & $\begin{array}{c}\text { Al 30 de junio } \\
\text { de 2015 }\end{array}$ & $\begin{array}{c}\text { Al 31 de marzo } \\
\text { de 2016 }\end{array}$ & $\begin{array}{c}\text { Al 30 de diciembre } \\
\text { de 2016 }\end{array}$ \\
\hline Operacionales & 1168 & 1285 & 1328 \\
\hline Comercializados & 919 & 929 & 942 \\
\hline $\begin{array}{c}\text { Porcentaje de } \\
\text { ocupación }\end{array}$ & $78.7 \%$ & $72.3 \%$ & $70.9 \%$ \\
\hline
\end{tabular}

Con base en estos datos se observa que hay frecuencias e incluso transpondedores completos que no son utilizados todo el tiempo. Por lo tanto, se puede decir que las frecuencias están siendo subutilizadas, ya que al ser frecuencias asignadas, otros usuarios 
o sistemas no pueden aprovechar estos espacios libres.

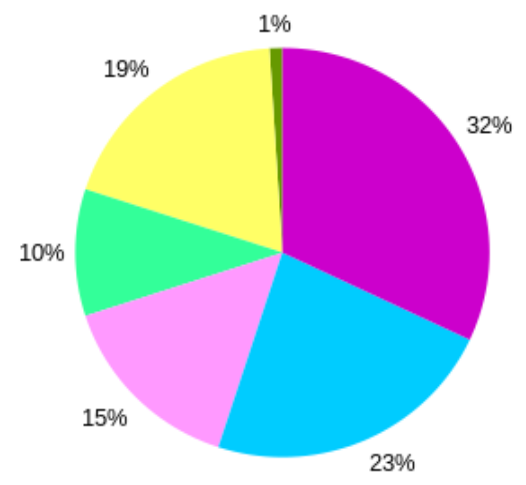

Plataforma Digital

Distribución de TV en Europa

Servicios IP

Distribución de TV en América

Redes VSAT, Punto a punto,

DAMA

Servicios Ocasionales

Figura 1. Distribución de utilización HISPASAT en $30^{\circ}$ Oeste.

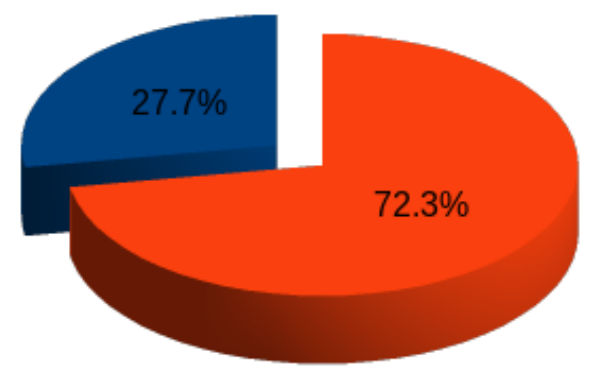

b)

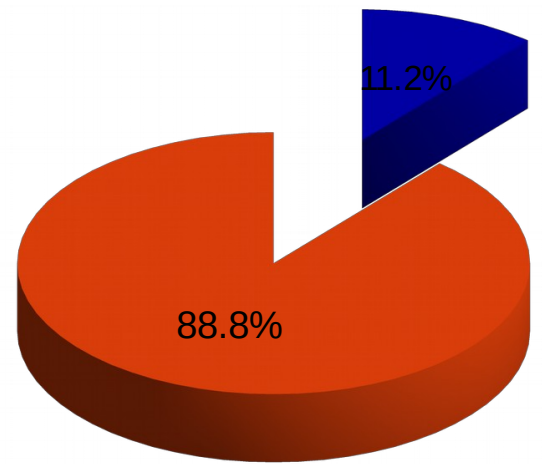

Espacio no utilizado

Espacio utilizado

Figura 2. Utilización de capacidad: a) Hispasat $61^{\circ} \mathrm{O}$, b) capacidad de la SES. 
Tomando la definición de [7], un satélite está compuesto principalmente por dos elementos: plataforma y carga útil. La plataforma consta de antenas, subsistemas de control orbital, posición, propulsión y energía; paneles solares, baterías y control térmico. Por otro lado, la carga útil está conformada por los transpondedores, es decir, equipo dedicado al proceso de transmisión y recepción de información.

Un transpondedor es un conjunto de componentes electrónicos que se tienen a bordo de un satélite, estos componentes crean un canal de comunicación con un ancho de banda, comúnmente de $36 \mathrm{MHz}$. Por lo regular, un satélite puede tener entre 24 y 72 transpondedores los cuales tienen una gran variedad de aplicaciones; por ejemplo, el envío de señales de televisión, voz y datos.

Por lo regular, las antenas trabajan en diferentes tipos de polarizaciones [8], los transpondedores, principalmente trabajan en dos tipos de polarizaciones: horizontal y vertical, con la finalidad de evitar interferencias y aprovechar una misma frecuencia para dos comunicaciones, siempre y cuando se encuentren en diferentes polarizaciones y conserven cierto nivel de potencia para no interferir en la polarización contraria.

En la Figura 3 se puede apreciar cómo es la asignación de transpondedores dentro del satélite, cabe mencionar que las frecuencias de subida son distintas a las de bajada. Específicamente, las frecuencias ascendentes son superiores a las descendentes, esto se hace para evitar interferencias y optimizar el uso de la potencia en el transpondedor ya que el suministro de energía se encuentra limitado [9]. 


\section{Frecuencia central, $\mathrm{MHz}$ Enlace ascendente}

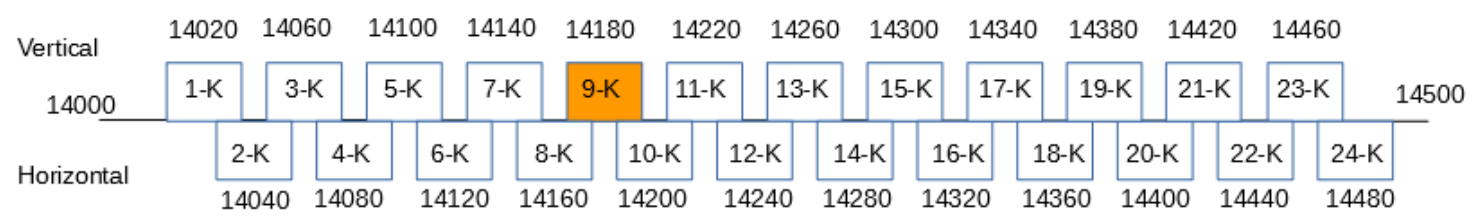

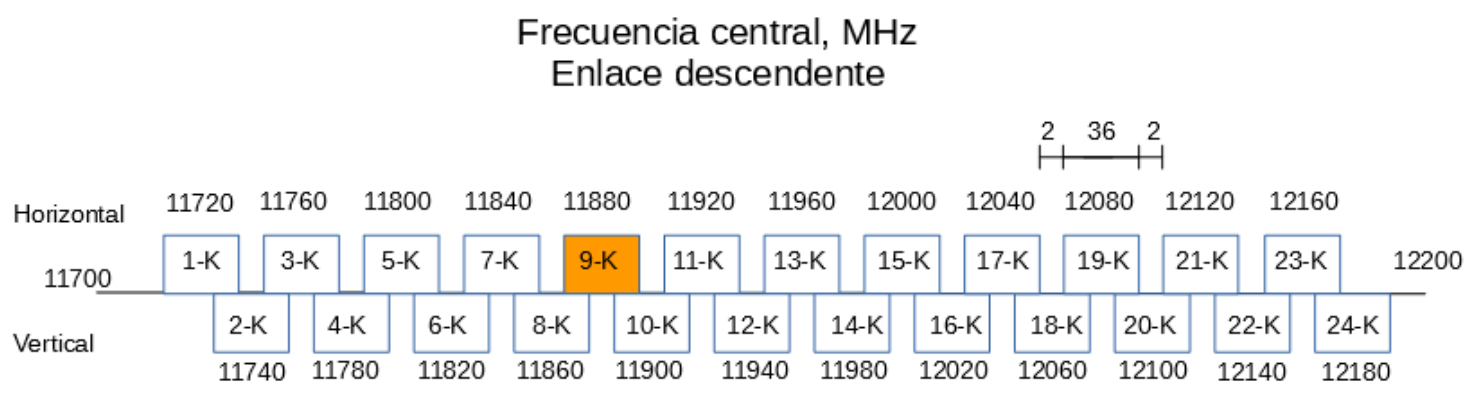

Figura 3. Asignación de 24 transpondedores dentro del satélite [9].

Por lo tanto, para aprovechar los espacios libres o huecos que se encuentran en el espectro, se han propuesto diversas técnicas a las que se les han denominado Acceso Dinámico al Espectro (DSA, por sus siglas en inglés). En la Figura 4 se observa el concepto de huecos en el espectro tal como se menciona en [10].

Para hacer una ocupación más eficiente del espectro, en distintos trabajos [11][15], por mencionar algunos, se ha propuesto utilizar la tecnología de los Radios Definidos por Software (SDR, por sus siglas en inglés), ya que estos cuentan con la capacidad de ser reconfigurables dependiendo de las demandas de la red y los usuarios, pues son equipos donde con el mismo hardware se pueden realizar diferentes funciones 
[14]. Los Radios Cognitivos (RC), están relacionados con la tecnología de los SDR y según IEEE (2006), se definen como un tipo de radio que puede detectar de forma autónoma, razonar sobre su entorno y adaptarse acorde a éste.

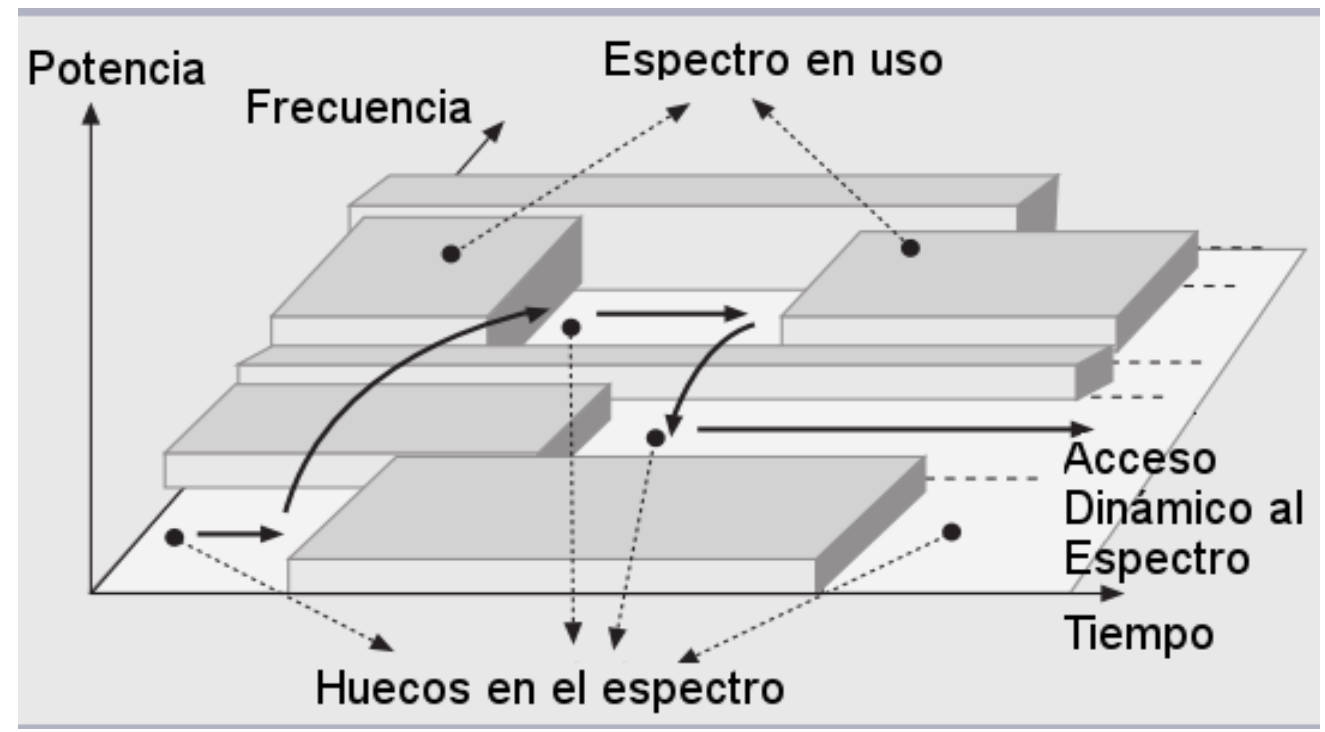

Figura 4. Concepto de huecos en el espectro [10].

Los RCs pueden detectar cuando existe un usuario primario en cierta frecuencia, de ser así, no se podrá utilizar este espacio y deberá buscar un hueco en el que no se esté transmitiendo información de un usuario primario. El usuario primario (UP) es aquél que tiene asignada cierta frecuencia, un usuario secundario (US) es aquel que no cuenta con una licencia para transmitir en alguna frecuencia, sin embargo, éste puede utilizar un espacio de frecuencias siempre y cuando no afecte al usuario primario.

Una vez que el RC encuentra un hueco, éste debe ser analizado para saber si cubre 
los requisitos mínimos para que el RC pueda transmitir, es decir, debe verificar que el ancho de banda sea adecuado, la probabilidad que el usuario primario utilice nuevamente la frecuencia, la capacidad de compartir el espectro, entre otros factores de la comunicación [10].

Según [15], un RC cuenta con dos características principales:

- Capacidad cognitiva: Interacción con el entorno en tiempo real para conocer los espacios vacíos en el espectro en un tiempo en específico. En el caso específico de este proyecto, la capacidad cognitiva de los RC se da en cierto momento en el "gestor", se explica con más detalle el algoritmo en el Capítulo 5.

- Reconfigurabilidad: Se refiere a la capacidad que tienen los RC para adaptarse a las variaciones que sufre, debido a que está constantemente cambiando de frecuencia, potencia, etc.

En [10] se propone un ciclo para poder gestionar el acceso al espectro en redes de radio cognitivos, el cual consta de cuatro etapas que se describen a continuación, en la Figura 5 se observa el ciclo cognitivo.

- Detección del espectro: Permite que los US detecten los espacios libres que se encuentran en el espectro y estos puedan adaptarse a ellos ocasionando un mínimo de interferencia al UP.

- Decisión del espectro: Los US deben ser capaces de decidir qué espacio detectado en el espectro es el que más le conviene utilizar de acuerdo a las características 
del enlace, ya que los huecos presentan diferentes características, por ejemplo, la probabilidad de que un UP utilice el espacio, el ancho de banda, frecuencia, niveles de interferencia y la potencia de ruido recibida.

- Espectro compartido: Los RCs deben ser capaces de compartir el espectro con otros usuarios y se requiere de la coordinación de los diferentes usuarios para poder acceder al espectro. Dicho proceso debe emplearse con un protocolo de acceso al medio, ya que se requiere la coexistencia de los UP con los US.

- Movilidad espectral: Debido a que hay coexistencia de UP con US, los RCs deben estar monitoreando el espectro y en caso de encontrar otro hueco, debe considerar cambiarse ya sea porque el UP ocupará su espacio o porque las condiciones del otro hueco son más apropiadas para seguir con la comunicación. La movilidad debe ser transparente y debe asegurar un traspaso rápido y con una afectación mínima en el rendimiento. 


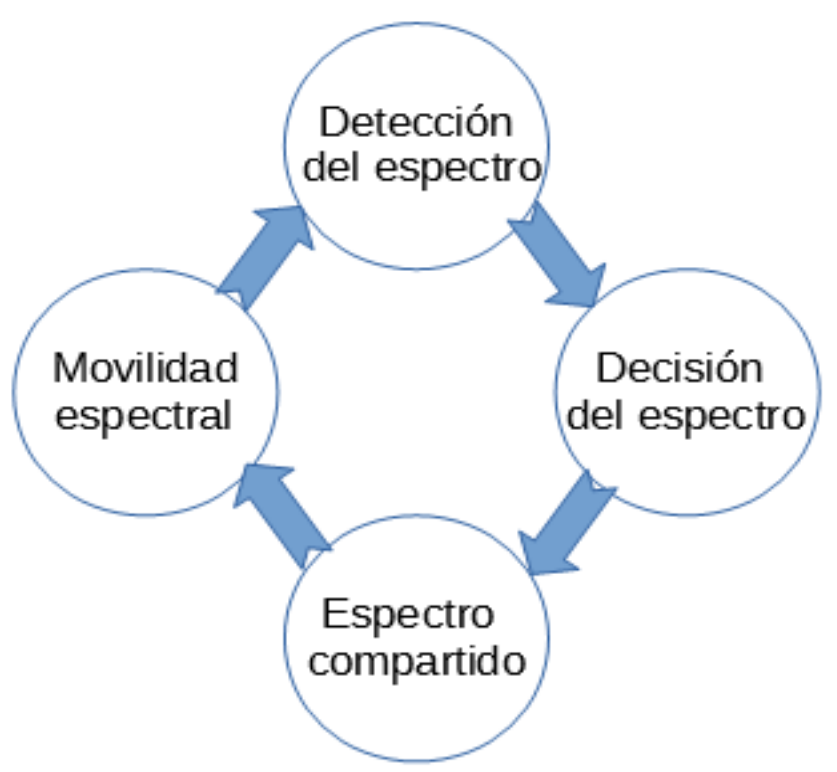

Figura 5. Ciclo cognitivo [10].

El objetivo de esta tesis es estudiar el acceso al medio en las comunicaciones satelitales utilizando técnicas TDMA/DAMA, también se hace un estudio de la asignación espectral con información de las empresas prestadoras de servicios satelitales. Además, se realizan simulaciones donde conviven estaciones primarias y secundarias por medio de un algoritmo propuesto para el acceso al espectro. 


\section{Capítulo 2. Estado del arte}

Desde 1999, cuando Joseph Mitola II introdujo el término de Radio Cognitivo en [14], se han propuesto diferentes aplicaciones para hacer uso de estos; las aplicaciones que se toman en cuenta para esta tesis son las que tienen que ver con las SatComs, ya que a diferencia de las comunicaciones terrestres, existe un tiempo de retardo significativo debido a la velocidad de propagación de las señales y a la distancia a la que se encuentran los satélites geoestacionarios, la cual es $35786 \mathrm{~km}$ [16].

En la búsqueda del Estado del Arte se ha encontrado hasta el momento que C. Morlet et al. en el año 2003, propusieron en [17], utilizar los RC como una opción para hacer uso de las frecuencias que no son utilizadas en los sistemas de comunicación satelital aprovechando los niveles de docilidad de programación con los que cuenta el satélite. En [18] se propone utilizar la flexibilidad de la comunicación entre el centro de control (NOC, por sus siglas en inglés) y el satélite para la configuración del software a través de la telemetría.

A partir de esta propuesta, algunos de los artículos más citados e importantes para las SatComs utilizando el concepto de RC son [14], [15], [17]-[19], en ellos se proponen implementaciones y diseños en las etapas de procesamiento digital. Específicamente en [19] se plantean tres paradigmas para el uso de RC en las SatComs, esto depende de las operaciones que deseen realizar los usuarios secundarios:

- Entrelazado, en donde los usuarios secundarios pueden utilizar una porción del espectro mientras no sea utilizado por el usuario primario, está basado en la 
comunicación oportuna, los espacios vacíos se pueden observar desde las dimensiones ortogonales de tiempo, espacio y frecuencia.

- Subyacente, el usuario secundario se superpone en la frecuencia del usuario primario asegurando que el nivel de interferencia está por debajo de un umbral determinado.

- Superposición, utiliza el conocimiento que tienen los US acerca de la transmisión de los UP y así selecciona un canal para realizar la transmisión con un nivel de interferencia aceptable, para lograr la comunicación con una relación mínima de interferencias respecto a la señal primaria.

También en [19], se presenta una clasificación del espectro de acuerdo a la utilización de éste, espacio blanco, espacio gris y espacio negro. El espacio blanco es el que está completamente vacío excepto por el ruido, el espacio gris está parcialmente ocupado por señales de interferencia y el espacio negro es el que está completamente ocupado por señales de comunicación, señales de interferencia y ruido.

Por otro lado, algunos artículos proponen el uso de algún algoritmo para implementar RC en sistemas de comunicación satelital, tal es el caso de [20] y [21], en donde se propone un módem 16QAM basado en CORDIC (del acrónimo Coordinate Rotation Digital Computer), el algoritmo se explica con mayor detalle en [22], este algoritmo típicamente se utiliza en $\mathrm{RC}$, ya que sirve para calcular funciones trigonométricas mediante la rotación de vectores, a su vez, la rotación de vectores sirve 
para convertir sistemas de coordenadas y funciones matemáticas como son, la Transformada Rápida de Fourier (FFT) y la Transformada Coseno Discreta (DCT). Con esta tecnología, los transpondedores podrían realizar las funciones de procesamiento digital de señales de una forma rápida [20].

También, se encontraron artículos que presentan los principios de un prototipo de procesador para RC que puedan ser reconfigurados desde la tierra utilizando la telemetría o telecomandos, con el fin de utilizar una arquitectura que denominan "procesador a bordo" (OBP, por sus siglas en inglés). Se explica con más detalle en [23] y [24] ya que en ambos artículos utilizan el mismo principio.

Estas investigaciones se habían estado basando en la posibilidad de utilizar los RC como un medio probable para la reutilización de frecuencias, utilizando telecomandos o telemetría para poder reconfigurar los SDR, en específico los RC. Sin embargo, en 2008, diferentes investigadores comenzaron a proponer la tecnología de los RC haciendo uso de los enlaces que no son utilizados todo el tiempo. Se encontró que con base en [25] surgieron algunas propuestas [26]-[35], las cuales utilizan los servicios que ofrecen los satélites ubicados en la órbita geoestacionaria, específicamente los que ofrecen servicio satelital fijo (FSS, por sus siglas en inglés). En [25] se propone un protocolo para evitar enlaces ocultos que pueden interferir en una comunicación satelital y proponen un escenario como el que se muestra en la Figura 6.

A partir de esta investigación, se han propuesto diferentes escenarios para utilizar los $\mathrm{RC}$ en las SatComs, dichas propuestas utilizan los enlaces de subida o bajada que no 
estén siendo utilizados por los usuarios primarios, con el fin de evitar interferencias que se puedan provocar por enlaces de microondas o servicios de difusión.

Para este proyecto de investigación, lo que se busca es dar prioridad a los UP al momento de hacer la reservación, y en caso de que no haya espacio disponible para estos usuarios, el "gestor" deberá disponer de un espacio aunque éste ya esté reservado por algún US, utilizar RC para evitar totalmente interferencias en las estaciones terrenas se contempla para un futuro lejano, cuando se tengan demasiadas estaciones terrenas en las que sí pueda haber un tipo de interferencia entre ellas.

Cabe mencionar, que los enlaces pueden ser de un solo satélite pero en diferente transpondedor, sin embargo, también se puede hacer uso de los enlaces disponibles de otros satélites que cuenten con FSS. El principal reto de las propuestas que involucran FSS, es que los satélites y/o transpondedores de un mismo satélite deben estar sincronizados para conocer los enlaces ocupados y los enlaces disponibles.

Como se mencionó anteriormente, después de la propuesta que se hizo en [25], en [35] se proponen algunos otros escenarios como se muestran en la Figura 7, y con base en su investigación, proponen algunos cambios técnicos para que los RC puedan utilizarse en las SatComs. Mencionan, por ejemplo, que algunas zonas cognitivas serían las más apropiadas de acuerdo a su nivel de potencia, proponen el empleo de bases de datos para conocer cuáles enlaces están siendo utilizados y cuáles son los que, con una mayor probabilidad, pueden utilizar una ranura de tiempo determinada. También, se menciona el 
monitoreo del espectro y la forma de haz como retos para lograr el uso de RC en las SatComs.

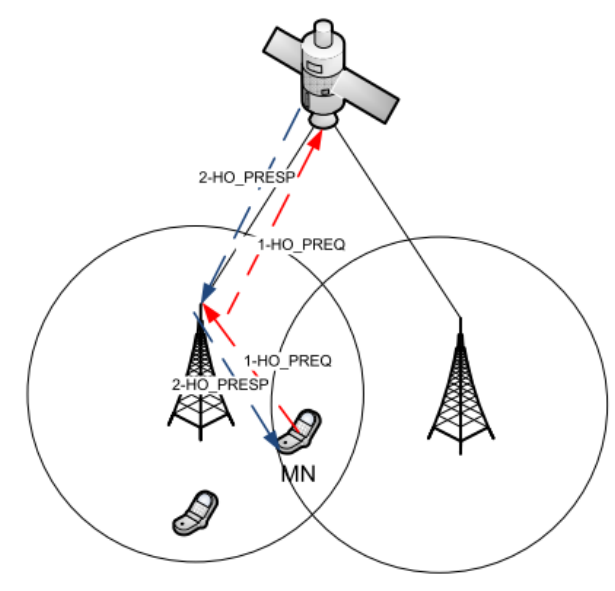

Figura 6. Escenario de una red satelital cognitiva propuesta en [25].

Los escenarios de la Figura 7, son en los que se basan las investigaciones de los artículos [25], [26], [28]-[30], [34], [35] , si bien sólo son tres escenarios, los artículos mencionados hacen uso de ellos (o alguno de ellos) para sus investigaciones, pruebas y propuestas, en donde se propone el uso de un enlace incumbente o primario y un enlace cognitivo o secundario el cual detecta la interferencia generada por una estación terrena y modifica sus parámetros para interferir lo menos posible al enlace incumbente. Las interferencias que detecta puede ser interferencia de una estación terrena, interferencia por usuarios terminales de FSS o interferencias ocasionadas por enlaces microondas.

Específicamente en [30], se propone una técnica para la estimación de interferencias en sistemas satelitales de RC. 

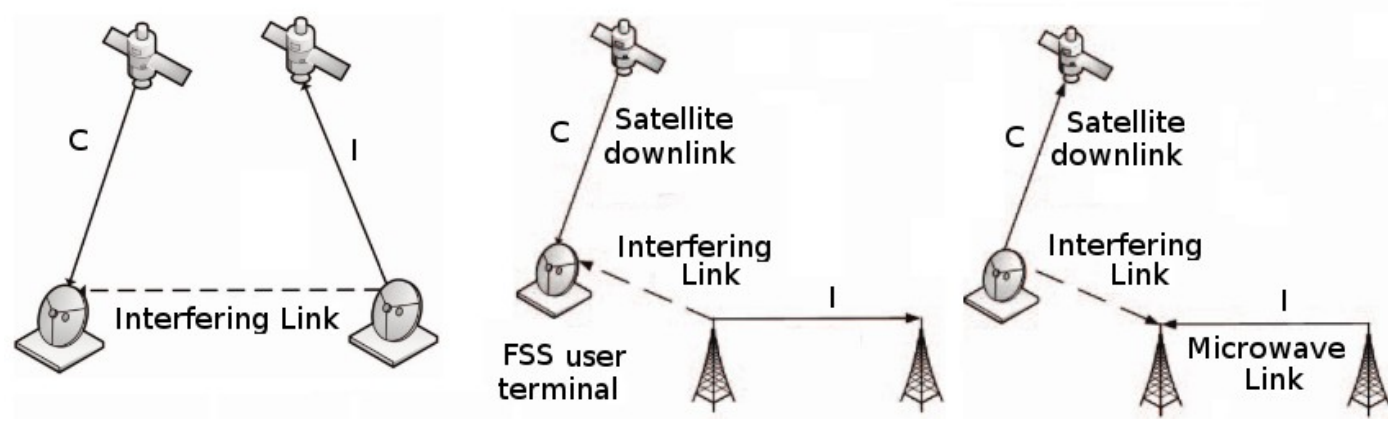

a)

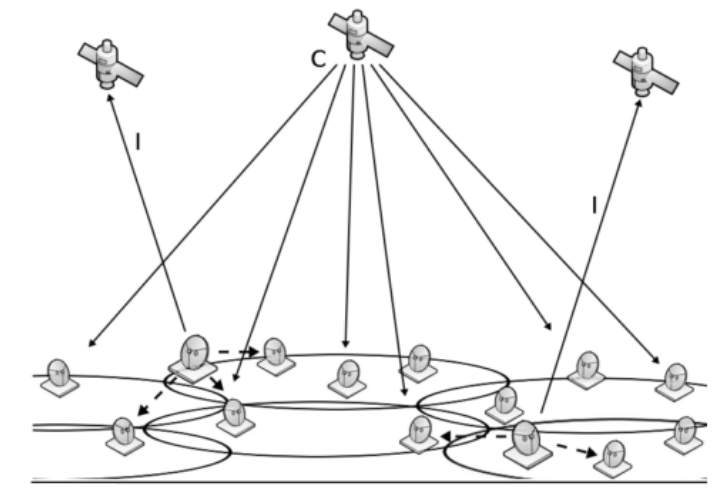

b)

Figura 7. a) Escenarios propuestos en [26], [28], [30], [33]-[37], b) Escenario propuesto en [29]. En donde: I - enlace perteneciente, C - enlace cognitivo.

Para poder calcular las interferencias y entender los enlaces satelitales, es necesario conocer los conceptos teóricos básicos, por lo que a continuación se explican algunos conceptos que son necesarios comprender para conocer la teoría detrás de los enlaces satelitales. 


\section{Capítulo 3. Marco teórico}

Un satélite geoestacionario se encuentra en una órbita cuya velocidad angular es igual a la de la tierra, es decir, aparenta una posición estacionaria respecto a un punto en la tierra. Dicha órbita se encuentra ubicada a 35786 km y su periodo de rotación es de 23 hrs, 56 minutos y 4 segundos [16].

Existen diferentes órbitas al rededor de la tierra, entre las más utilizadas para las comunicaciones satelitales son las órbitas; bajas (LEO, por sus siglas en inglés) a una altura entre 200 y $1200 \mathrm{~km}$ de la superficie terrestre; medias (MEO, por sus siglas en inglés) se ubican a una distancia aproximada de $10000 \mathrm{~km}$ de la superficie terrestre; y geoestacionaria o geosíncrona (GEO, por sus siglas en inglés) cuya altitud es aproximadamente $36000 \mathrm{~km}$ [7]. Para las órbitas LEO y MEO, el retardo de propagación respecto a la órbita GEO es menor, sin embargo, los tiempos de observación de los satélites es limitado y existe el problema de corrimiento de frecuencia debido al efecto Doppler. En los satélites GEO, no existen este tipo de problemas ya que la velocidad relativa entre las estaciones terrenas y el satélite es cero y no existen corrimientos de frecuencia por el efecto Doppler. Sin embargo, el mayor problema con los satélites GEO es el tiempo de propagación y el aumento de atenuación de la señal debido a las pérdidas por trayectoria que se incrementan por la distancia. En la Figura 8 se ilustran las órbitas antes mencionadas.

Para este proyecto de investigación se propone el uso de los satélites en la órbita geoestacionaria, ya que desde un punto fijo en la tierra, el satélite se encuentra 
estacionario por lo que en las simulaciones se utilizan estos satélites.

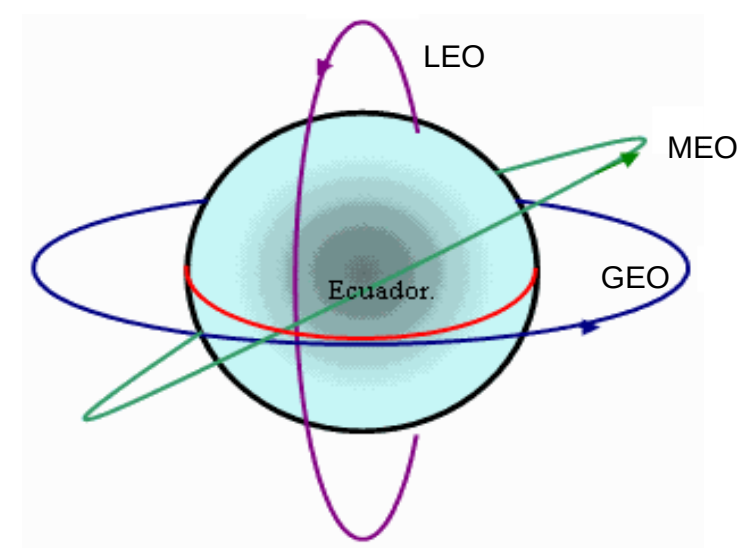

Figura 8. Órbitas satelitales.

\subsection{Satélites Geoestacionarios}

Para llevar a cabo esta tesis, se hace uso de satélites geoestacionarios para las pruebas, ya que estos satélites coinciden con la velocidad de rotación que tiene la tierra; por lo tanto, se ven como si estuvieran fijos y por ende es más fácil trabajar con estos debido a que las antenas transmisoras y receptoras no deben moverse de lugar.

Existen dos tipos de satélites geoestacionarios, los de tipo 'bent-pipen y los 'regenerative", para las pruebas de esta tesis se utilizaron satélites del tipo 'regenerative', ya que en el Capítulo 5 se propone un procesamiento dentro del satélite.

1 Que no hace procesamiento a bordo o un cambio de enlace [9].

2 Que realiza algún tipo de procesamiento a bordo o un cambio de enlace [9]. 
Las comunicaciones satelitales tienen tres etapas principales para poder realizar una comunicación adecuadamente: los enlaces ascendentes, los canales o transpondedores y los enlaces descendentes, observe la Figura 9. Los enlaces ascendentes y descendentes se hacen a través de estaciones terrenas, éstas modulan, cambian de frecuencia, filtran y amplifican las señales. Los transpondedores se encuentran dentro del satélite y son el núcleo del satélite ya que son los encargados de filtrar las señales, las amplifican y cambian de frecuencia para enviarlas de nuevo a la tierra.

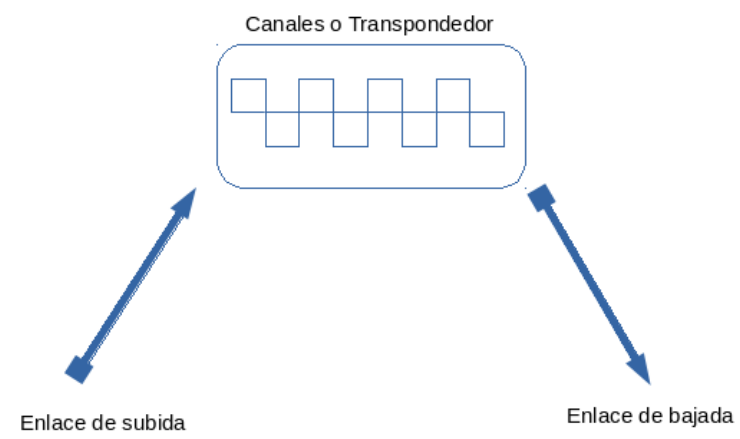

Figura 9. Comunicación satelital

Las señales que van de las estaciones terrenas al satélite y viceversa, tienen un tiempo de propagación de aproximadamente $120 \mathrm{~ms}$, ya que la distancia que debe recorrer la señal no puede despreciarse, para poder comprobarlo se hacen algunos cálculos, los cuales se muestran en la Ecuación 1. Los valores requeridos para este cálculo son, velocidad de propagación que corresponde a la velocidad de la luz 
$3 \times 10^{8} \mathrm{~m} / \mathrm{s}$, la distancia entre las estaciones terrenas y el satélite geoestacionario que es aproximadamente de $36000 \mathrm{~km}$, por lo tanto:

$$
v=\frac{d}{t} \quad \text { donde } \quad t \simeq \frac{d}{v}=\frac{36000 \mathrm{~km}}{3 \times 10^{8} \mathrm{~m} / \mathrm{s}}=0.12 \mathrm{~s}
$$

Donde el tiempo de ida y vuelta (RTT, por sus siglas en inglés) es de aproximadamente $240 \mathrm{~ms}$. Cabe mencionar que en este tiempo RTT, no se considera ningún tipo de procesamiento dentro del satélite, por lo que el satélite considerado para este cálculo es del tipo bent-pipe, si se quisiera considerar un satélite de tipo regenerative, se debe sumar el tiempo de procesamiento dentro del satélite.

\subsection{Cálculos de enlace}

Es importante conocer algunos de los parámetros utilizados para los cálculos de enlace ya que gracias a estos, se tienen los datos teóricos de las comunicaciones satelitales y sirve para que se pueda completar de forma correcta la comunicación, además de servir para probar que las simulaciones tienen los datos correctos de entrada y comprobar los datos de salida con base en los resultados teóricos.

Uno de los parámetros más importantes en el cálculo de enlaces es la Potencia Isotrópica Radiada Efectiva (PIRE), es decir, la cantidad de potencia que está llegando al 
transpondedor y a la estación terrena, sin embargo, depende de la ganancia de la antena que la recibe (antena receptora) o transmite (antena transmisora); la PIRE se encuentra dada como se muestra en la Ecuación 2 y la potencia recibida en la Ecuación 3.

$$
\begin{aligned}
& \operatorname{PIRE}(d B W)=P_{T}(d B W)+G_{T}(d B) \\
& P_{R}(d B m)=\operatorname{PIRE}(d B m)+G_{R}(d B)-A_{T}
\end{aligned}
$$

Donde $\mathrm{P}_{\mathrm{T}}$ es la potencia transmitida; $\mathrm{G}_{\mathrm{T}}$ es la ganancia de la antena transmisora; $\mathrm{P}_{\mathrm{R}}$ es la potencia recibida; $\mathrm{G}_{R}$ es la ganancia de la antena receptora; $\mathrm{A}_{\mathrm{T}}$ es la atenuación por temperatura y por pérdidas por trayectoria, entre otros factores.

También, es necesario tener en cuenta la velocidad de transmisión (R) para conocer el número máximo de bits que se pueden transmitir en cierto tiempo (t), para este cálculo se utiliza la siguiente relación:

$$
\# \text { bits }=R \times t
$$

Del mismo modo, es deseable conocer la capacidad del canal, cuya ecuación se muestra en (5).

$$
N=\frac{T}{L / R}
$$

Donde ' $\mathrm{N}$ ' es el número de mensajes transmitidos, ' $\mathrm{T}$ ' es el tiempo total, ' $\mathrm{L}$ ' se refiere a la longitud del mensaje y ' $R$ ' es la velocidad del canal.

Por otro lado, las pérdidas de propagación en los enlaces de subida y bajada están dadas por la ecuación (6).

$$
\left[\mathrm{C}_{\mathrm{dBW}}\right]_{\mathrm{subida}}=[\mathrm{PIRE}]_{\mathrm{dBW}}+\left[\mathrm{G}_{\mathrm{R}}\right]_{\mathrm{dBi}-}[\mathrm{FSLP}]_{\mathrm{dB}}
$$


Donde FSLP es la atenuación por propagación en el espacio libre, y está dada por la ecuación (7).

$$
\begin{gathered}
\text { FSLP }=\left(\frac{4 \pi d}{\lambda}\right)^{2} \\
\text { Donde } \quad \lambda=\frac{c}{f}
\end{gathered}
$$

Sabiendo que ' $d$ ' es la distancia, 'c' es la velocidad de la luz $3 \times 10^{8} \mathrm{~m} / \mathrm{s}$ y 'f' es la frecuencia de operación.

Cabe mencionar que existen diferentes tipos de pérdidas en los enlaces satelitales; pérdidas por mal apuntamiento, pérdidas por conectores y atenuación atmosférica, por nombrar algunos, y estas pérdidas deben sumarse a las atenuaciones.

Al hablar de una comunicación, en este caso satelital, se debe tener en cuenta el ruido térmico en la comunicación, la Ecuación 9 muestra el cálculo de dicho ruido.

$$
\mathrm{N}=\mathrm{kTB}
$$

Donde ' $\mathrm{T}$ ' es la temperatura de ruido, ' $\mathrm{k}$ ' corresponde a la constante de Boltzmann $\left(1.38 \times 10^{-23} \mathrm{~J} / \mathrm{K}\right) \mathrm{y}$ 'B' es el ancho de banda.

La relación portadora a ruido $\left(\mathrm{C} / \mathrm{N}_{0}\right)$ está dada por la Ecuación 10 .

$$
\frac{C}{N_{0}}=P I R E-F S L P+\frac{G}{T}-10 \times \log (k)
$$

Donde ' $G$ ' es la ganancia de la antena, ' $T$ ' es la temperatura de ruido y ' $k$ ' corresponde a la constante de Boltzmann ( $\left.1.38 \times 10^{-23} \mathrm{~J} / \mathrm{K}\right)$. 
Otro parámetro a considerar es lo que se conoce como Eb/No normalizada, que se refiere a la energía de bit $(\mathrm{Eb})$ por la densidad espectral de ruido promedio (No), la cual está dada de la siguiente manera:

$$
\frac{E_{b}}{N_{o}}=\frac{S}{N} \times \frac{B w}{R}
$$

Donde 'S' hace referencia a la potencia de la señal, ' $N$ ' es la potencia de la señal de ruido, 'Bw' es el ancho de banda y 'R' se refiere a la velocidad de transmisión.

\subsection{Frecuencias satelitales}

Las frecuencias asignadas a las comunicaciones satelitales, se encuentran en el orden de los Giga Hertz, y como se había mencionado anteriormente las frecuencias descendentes son menores que las ascendentes debido a que a mayor frecuencia, más atenuación sufre la señal; sin embargo, en el enlace de subida se puede manipular un poco más la señal modificando ciertos parámetros (por ejemplo, la potencia) para que la señal llegue mejor al satélite, cosa que es casi imposible hacer en el satélite para mejorar el envío de la señal a las estaciones terrenas ya que sus recursos energéticos son limitados. Las frecuencias de las portadoras satelitales son mayores a $1 \mathrm{GHz}$, así el ruido producido por causas naturales se puede despreciar, cosa que no se podría hacer en frecuencias menores [38].

Existen, diferentes bandas de frecuencias de subida y bajada, popularmente se les denomina con letras tal como se muestra en la Tabla 2.

Para esta tesis, la banda de frecuencias es independiente de los resultados, ya que 
el mecanismo de acceso está pensado para que funcione para cualquier banda de frecuencia, siempre y cuando el satélite sea geoestacionario, para que las antenas se mantengan fijas y la visión al satélite se tenga todo el tiempo cosa que no ocurriría si se trabaja con los satélites de otra órbita.

Tabla 2. Bandas de frecuencias para comunicaciones satelitales [39].

\begin{tabular}{|l|c|c|c|}
\hline \multicolumn{1}{|c|}{ Banda } & $\begin{array}{c}\text { Frecuencia de subida } \\
(\mathbf{G H z})\end{array}$ & $\begin{array}{c}\text { Frecuencia de bajada } \\
\mathbf{( G H z )}\end{array}$ & Tipos de servicios satelitales \\
\hline $\mathrm{L}(1.5-2 \mathrm{GHz})$ & $1.61-1.66$ & $1.452-1.61$ & Comunicaciones móviles \\
\hline $\mathrm{S}(2-3 \mathrm{GHz})$ & $2.025-2.69$ & $2.29-2.5$ & $\begin{array}{c}\text { Comunicaciones móviles, fijas y } \\
\text { radiodifusión }\end{array}$ \\
\hline $\mathrm{C}(4-6 \mathrm{GHz})$ & $5.925-6.425$ & $3.7-4.2$ & Intelsat, satélites nacionales \\
\hline $\mathrm{X}(7-8 \mathrm{GHz})$ & $7.925-8.425$ & $7.25-7.75$ & $\begin{array}{c}\text { Satélites gubernamentales y } \\
\text { militares }\end{array}$ \\
\hline $\mathrm{Ku}(11-13 \mathrm{GHz})$ & $12.75-14.5$ & $10.7-12.75$ & $\begin{array}{c}\text { Intelsat, Eutelsat, satélites } \\
\text { nacionales, DBS }\end{array}$ \\
\hline $\mathrm{Ka}(30-20 \mathrm{GHz})$ & $27.5-31$ & $17.2-21.2$ & $\begin{array}{c}\text { Japón, Europa, USA, enlaces } \\
\text { intersatelitales }\end{array}$ \\
\hline
\end{tabular}

\subsection{Control de acceso al medio}

Una de las características más importantes en las SatComs, es el tipo de control de acceso al medio con el que se cuenta, ya que sirve para aprovechar el espectro de frecuencias como la sincronización y multiplexación de señales, con el fin de evitar errores en la comunicación. Los protocolos más utilizados según [37] son: 
- FDMA: Acceso Múltiple por División de Frecuencia, divide el total del ancho de banda del transpondedor en bandas más pequeñas para que más usuarios puedan utilizarlo y se debe asignar una banda de frecuencia de guarda de cada lado de la comunicación para evitar interferencias, los usuarios pueden transmitir continuamente mientras no utilicen más ancho de banda del asignado, tal como se observa en la Figura 10.

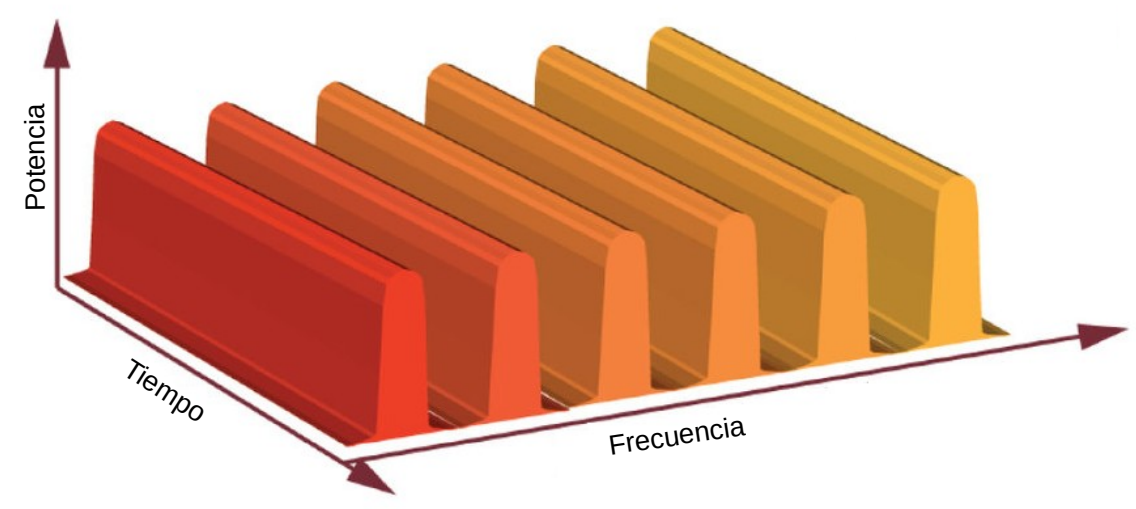

Figura 10. Comunicación utilizando un control de acceso al medio FDMA.

- TDMA: Acceso Múltiple por División de Tiempo, divide el total de tiempo de transmisión, es decir, las estaciones transmiten periódicamente, por lo que cada una tiene asignado un turno para poder transmitir, se debe tener un tiempo de guarda de cada lado para evitar interferencias, observe la Figura 11. En los sistemas basados en TDMA, la sincronización es un factor clave para la correcta operación del mismo.

- CDMA: Acceso Múltiple por División de Código, las estaciones pueden transmitir simultáneamente y continuamente por la banda de frecuencia, sin embargo, cada transmisión lleva un código el cual se combina con la información del transmisor, 
este tipo de acceso utiliza la tecnología de espectro expandido tal como se muestra en la Figura 12.

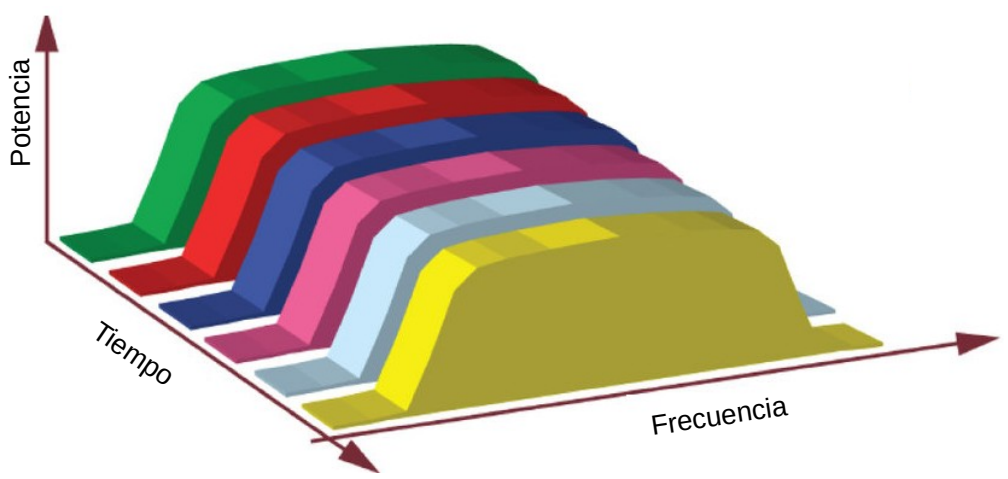

Figura 11. Comunicación utilizando un control de acceso al medio TDMA.

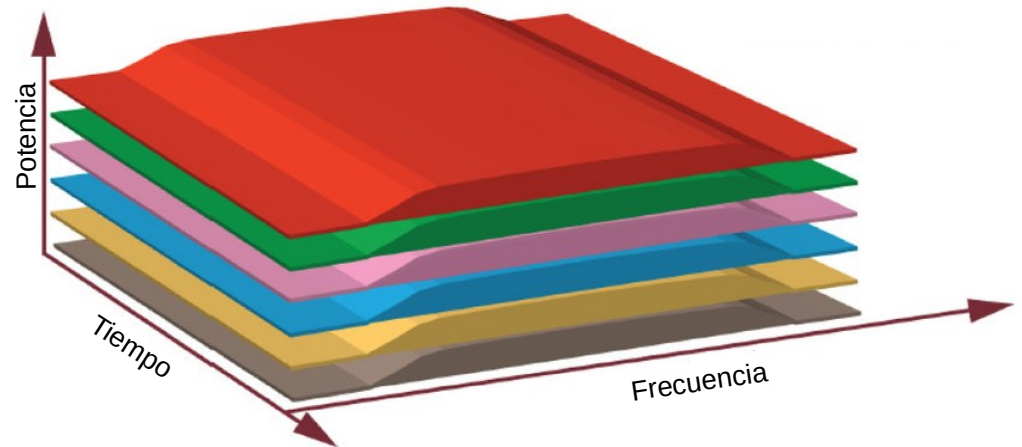

Figura 12. Comunicación utilizando un control de acceso al medio CDMA.

- DAMA: Acceso Múltiple Asignado bajo Demanda, las estaciones no tienen asignado de forma permanente un segmento de frecuencia, por lo que si se desea establecer una comunicación, se le asignará una frecuencia que se encuentre desocupada. 
Dicha frecuencia se vuelve a asignar a otro usuario en cuanto se vuelva a desocupar.

- FAMA: Acceso Múltiple de Asignación Fija, contrario a DAMA, en este tipo de acceso múltiple se cuenta con una frecuencia asignada previamente, para que sea utilizada cada vez que se quiere establecer una comunicación.

Estos dos últimos, DAMA y FAMA, son utilizados en combinación con alguno de los primeros tres, es decir, se puede tener una acceso al medio del tipo FDMA/DAMA o FDMA/FAMA; TDMA/DAMA o TDMA/FAMA; CDMA/DAMA o CDMA/FAMA. Esto es debido a que únicamente se define si el acceso es fijo o bajo demanda, sin embargo, no determina el tipo de acceso al medio y por eso depende de una preasignación del acceso al medio, con estas combinaciones aumenta la eficiencia de las comunicaciones satelitales. Para este trabajo, se hace uso de TDMA/DAMA para poder resolver el acceso al espectro, esto de acuerdo a la propuesta que se realiza en el Capítulo 5.

Existen otros tipos de acceso al medio denominados acceso dinámico por control centralizado, los cuales requieren de reservación previa, a los que se les conoce como Método de Acceso por Reserva; es decir, a cada usuario que desee transmitir información, se le debe asignar un espacio y un tiempo para que pueda realizar la comunicación. Para estos fines, es necesario contar con un gestor encargado de escuchar las peticiones de los usuarios, así podrá asignar la reserva para cada uno de ellos. Para esta tesis se utiliza un acceso al medio por reservación, se explica el algoritmo propuesto en el Capítulo 5. 


\section{Capítulo 4. Entorno de simulación}

Una simulación es el proceso de diseñar y desarrollar un proceso real en un ambiente artificial, ya que no siempre se pueden realizar pruebas experimentales ya sea por falta de material, porque es costoso o porque las condiciones de trabajo no lo permiten. Por ejemplo, para esta tesis, sería muy costoso hacer pruebas sobre enlaces satelitales reales, por tal motivo se ha decidido utilizar un simulador. Esta técnica es empleada para diseñar el ambiente de aplicación deseado con base en los datos teóricos del ambiente, esto permite hacer más real el escenario de simulación.

\subsection{Simulador NS-2}

Para esta tesis se propone el uso del simulador NS-2, un simulador de eventos discretos utilizado para redes tanto alámbricas como inalámbricas, el cual permite simular protocolos unicast y multicast. Cuenta con algunas bibliotecas para poder simular comunicaciones satelitales, utilizando satélites geoestacionarios ya sea como repetidores o como satélites con procesamiento.

También, es capaz de simular satélites en órbita baja, sin embargo para esta investigación no serán considerados. El simulador tiene una herramienta de visualización llamada "NAM", sin embargo, las simulaciones de comunicaciones satelitales no son compatibles con este visualizador, por lo que sólo se pueden obtener las trazas y después graficarlas con una herramienta externa, para esta tesis se decidió utilizar GNUPlot, que 
es un programa basado en comandos que puede graficar funciones en $2 \mathrm{D}$ y $3 \mathrm{D}$, además de ser software libre.

NS, es un software libre y fue desarrollado en $\mathrm{C}++$, provee una interfaz de simulación a través de una variante orientada a objetos de Tcl, en la Figura 13 se observa la arquitectura del simulador NS-2. Para este proyecto se hizo uso del sistema operativo Arch Linux, por lo que el simulador NS-2 se encuentra en los repositorios del mismo, por lo que ya no hay necesidad de compilar NS-2.

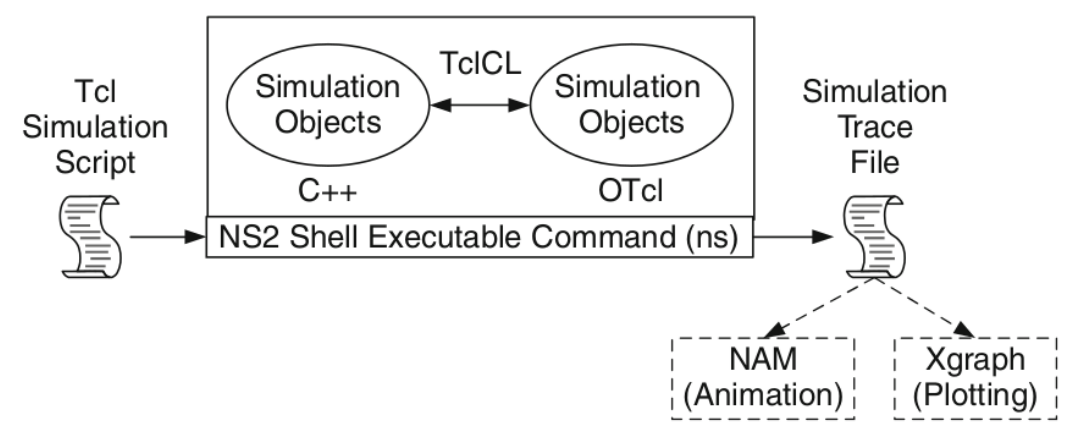

Figura 13. Arquitectura básica de NS [40].

\subsection{Ejecución del simulador NS-2}

Para llevar a cabo la simulación es necesario abrir una terminal y ubicarnos en la carpeta donde se encuentra el archivo del script en '.tcl'. Una vez instalado NS-2 en la computadora, en la terminal escribimos "ns archivo.tcl" y saldrán los mensajes en la terminal y comenzará la simulación, se debe esperar unos segundos y cuando finalice la simulación se creará un archivo llamado "out.tr" el cual contiene las trazas de la salida de 
la simulación, tal como se muestra en la Tabla 3.

Tabla 3. Fragmento de traza de la simulación.

$\begin{array}{rrrllllllllllll}- & 0.1618 & 0 & 4 & \operatorname{cbr} 210 & -- & 3.0 & 4.0 & 19 & 19 & -61.0 & 4.7 & -61.0 \\ + & 0.1632 & 3 & 0 & \operatorname{cbr} 210 & -- & 3.0 & 4.0 & 97 & 97 & 19.32 & -99.08 & -61.0 \\ r & 0.1636 & 3 & 0 & \operatorname{cbr} 210 & - & 3.0 & 4.0 & 100 & 20 & 19.32 & -99.08 & -61.0 \\ \mathrm{~d} & 0.1636 & 0 & 4 & \operatorname{cbr} & 210 & - & - & 3.0 & 4.0 & 120 & 120 & -61.0 & 4.70 & -61.0\end{array}$

La traza muestra en la primera columna diferentes caracteres, en la Tabla 4 se muestran los caracteres de la traza.

Tabla 4. Significado de los caracteres en la traza para la columna 1.

\begin{tabular}{|c|c|c|c|}
\hline+ & Entrada del paquete al buffer & - & Salida del paquete del buffer \\
\hline r & Paquete Recibido & d & Paquete Perdido \\
\hline e & Error en la recepción de paquete & \multicolumn{2}{|c}{} \\
\cline { 1 - 2 } & &
\end{tabular}

En la Tabla 5 se muestra el contenido de las columnas 2 a la 13.

Tabla 5. Contenido de cada columna en la traza de salida de la simulación.

\begin{tabular}{|c|c|c|c|c|c|}
\hline Columna 2 & Columna 3 & Columna 4 & Columna 5 & Columna 6 & Columna 7 \\
\hline Tiempo & Nodo origen & Nodo destino & $\begin{array}{c}\text { Tipo de } \\
\text { tráfico }\end{array}$ & $\begin{array}{c}\text { Tamaño del } \\
\text { paquete }\end{array}$ & $\begin{array}{c}\text { Nodo } \\
\text { transmisor }\end{array}$ \\
\hline Columna 8 & \multicolumn{2}{|c|}{ Columna 9 y 10 } & \multicolumn{2}{|c|}{ Columna 11 y 12 } & Columna 13 \\
\hline $\begin{array}{c}\text { Nodo } \\
\text { receptor }\end{array}$ & \multicolumn{2}{|c|}{ Número de evento } & $\begin{array}{c}\text { Coordenadas del nodo } \\
\text { origen }\end{array}$ & $\begin{array}{c}\text { Ubicación del } \\
\text { satélite }\end{array}$ \\
\hline
\end{tabular}




\subsection{Modificación del NS-2}

Para poder realizar las simulaciones, se hizo una modificación en el programa ya que no permitía valores de paquetes CBR (Constant Bit rate) mayores a 1000B, para realizar este cambio se accedió a la siguiente dirección /ns-2.35/tcl/lib/ns-default.tcl, y en la línea Agent/UDP set packetSize se pone el número en bits del tamaño del paquete que se desea, en este caso se puso 12000, por lo que la línea quedó “Agent/UDP set packetSize_ 12000”. Con este cambio, se puede tener paquetes de hasta 1500 bytes, en el tráfico CBR. Una vez que se hizo el cambio, se debe volver a compilar el simulador como se muestra en [41].

\subsection{Throughput}

Se le denomina 'throughput' o rendimiento a la cantidad de bits recibidos en una comunicación respecto a los bits enviados. Para poder calcular el throughput en NS-2, es necesario crear un script en perl '.pl' el cual es el encargado de hacer el cálculo del throughput y graficarlo haciendo uso de gnuplot, en la Figura 14 se muestra un ejemplo del throughput en la simulación, sin embargo, en el Capítulo 6 se muestran más gráficas y su análisis.

Los datos para calcular throughput se obtienen del la traza de salida del simulador y el código completo del throughput se encuentra en el ANEXO A. 


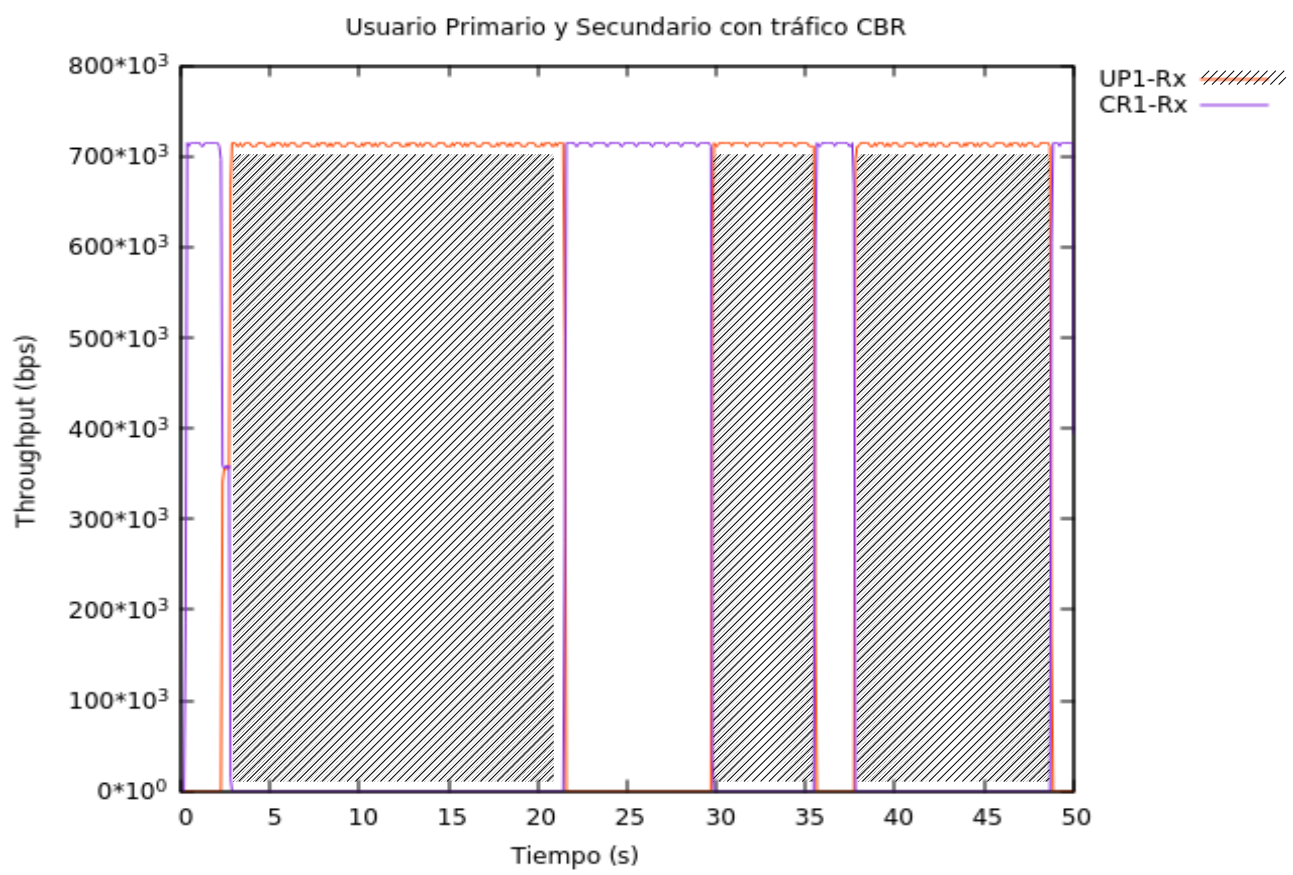

Figura 14. Ejemplo de throughput vs tiempo, usuarios primarios y secundarios. 


\section{Capítulo 5. Propuesta}

El objetivo de la propuesta de investigación es la utilización de RC para aprovechar los espacios libres en las comunicaciones satelitales, se realizaron simulaciones con diferentes escenarios en donde se tiene un satélite geoestacionario, estaciones primarias y estaciones secundarias, el código de la simulación se muestra en el ANEXO B.

En la Figura 15 se ilustra un primer escenario que consiste en: un satélite, una estación primaria transmisora, una estación primaria receptora, una estación secundaria transmisora y una estación secundaria receptora.

El objetivo de estas simulaciones es hacer que los UP y US convivan en un mismo entorno, en donde los US envían información cuando el UP no lo hace, los huecos los asigna el gestor, dependiendo de cómo se vayan solicitando. La mínima ranura que se puede asignar es de 360ms, la justificación se da en la Ecuación 12. La ocupación que tendrán los UP corresponderá a los porcentajes $12 \%, 28 \%$ y $72 \%$ por parte de los UP con el fin de probar diferentes escenarios, cabe mencionar que el $72 \%$, se da por la investigación en el estado del arte dónde las empresas prestadoras de servicios tienen una ocupación aproximada a 72\% [4]-[6].

En los escenarios que cuentan con más de dos estaciones secundarias, se propone un acceso al medio por reservación TDMA/DAMA, donde se propone utilizar un 'gestor' dentro del satélite el cual contiene la información de las estaciones primarias, de acuerdo a la reservación que éstas realizan previamente. 


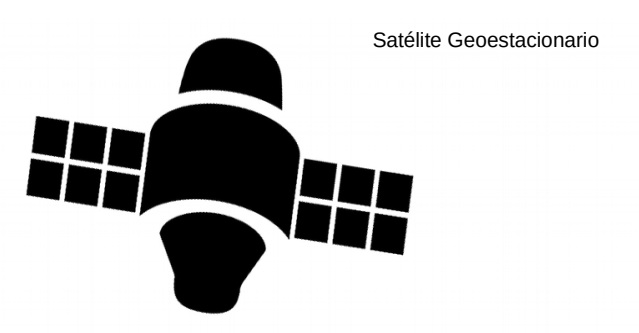

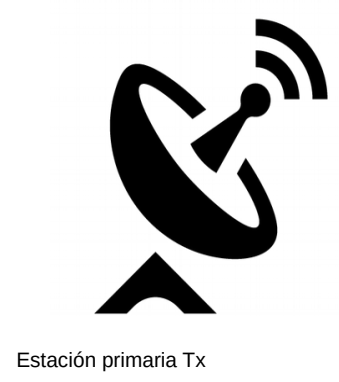

Estación secundaria Tx

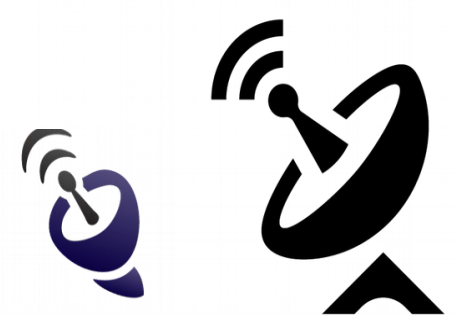

Estación secundaria Rx
Estación primaria $\mathrm{Rx}$

Figura 15. Primer escenario propuesto con dos estaciones secundarias y dos estaciones primarias.

La prioridad la tienen indiscutiblemente los UP, por lo tanto, hasta que no haya UP que quieran reservar espacio, los US podrán hacerlo. En la Figura 16 se ilustran los pasos a seguir para cuando un UP pide reserva de un espacio.

Una vez hechas las reservaciones de los UP, el gestor envía por medio de un broadcast la información que tiene acerca de los espacios disponibles en el transpondedor, con el fin de que llegue esta información a los US que estén escuchando y así puedan reservar alguno de los espacios disponibles que dejaron los UP. 


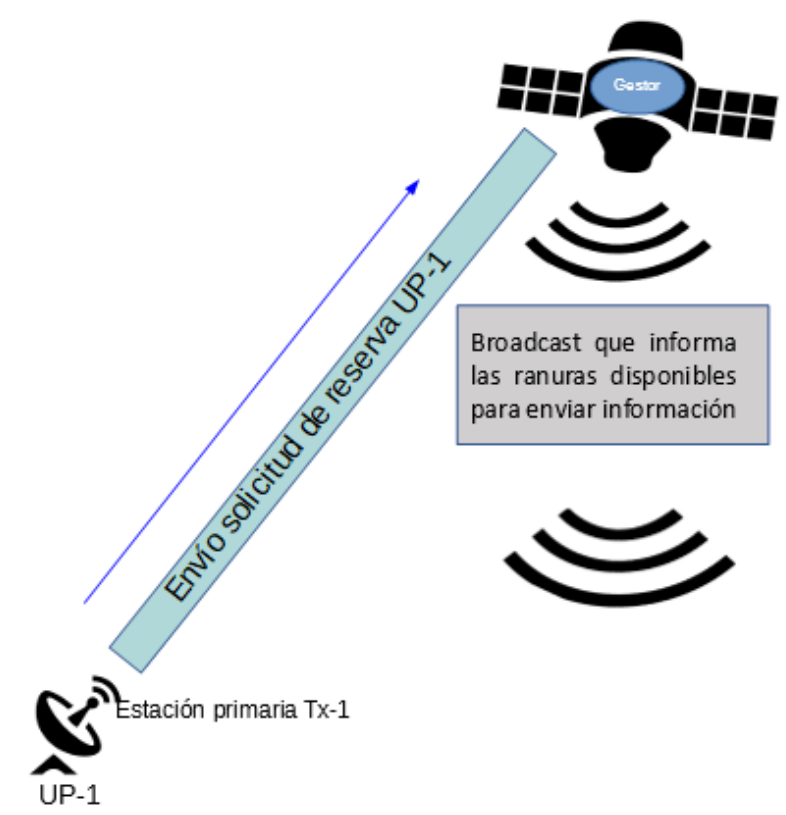

Buffer 1 de reservación primaria, escucha las peticiones de las estaciones

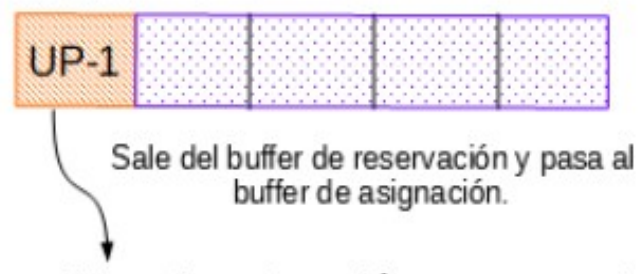

Buffer 2 de asignación, se van asignando las ranuras disponibles conforme se van solicitando en el buffer 1.

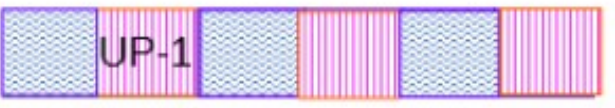

UP solicitando una ranura

Espacio disponible en Buffer 1

Ranuras asignadas a UP

Ranuras disponibles para asignar a UP

Ranuras disponibles para asignar aUS

Figura 16. Envío de información del UP-1 al gestor.

La asignación secundaria se hará conforme los US envíen solicitud de reservación, por medio de un TDMA/DAMA, tal como se especifica en el Capítulo 3. En la Figura 17 se observan los pasos a seguir para que los huecos sean llenados con las 
solicitudes de los US.

Cabe mencionar que en caso de contención por parte de los usuarios al momento de pedir reservación, se detendrá el proceso de solicitud de reserva y por medio de un tiempo aleatorio asignado a cada usuario, se reanudará el proceso. Una vez hecha la reservación, no debería haber colisiones ya que se habrán asignado los tiempos de transmisión a cada usuario, esto aplica tanto en los UP como en los US.

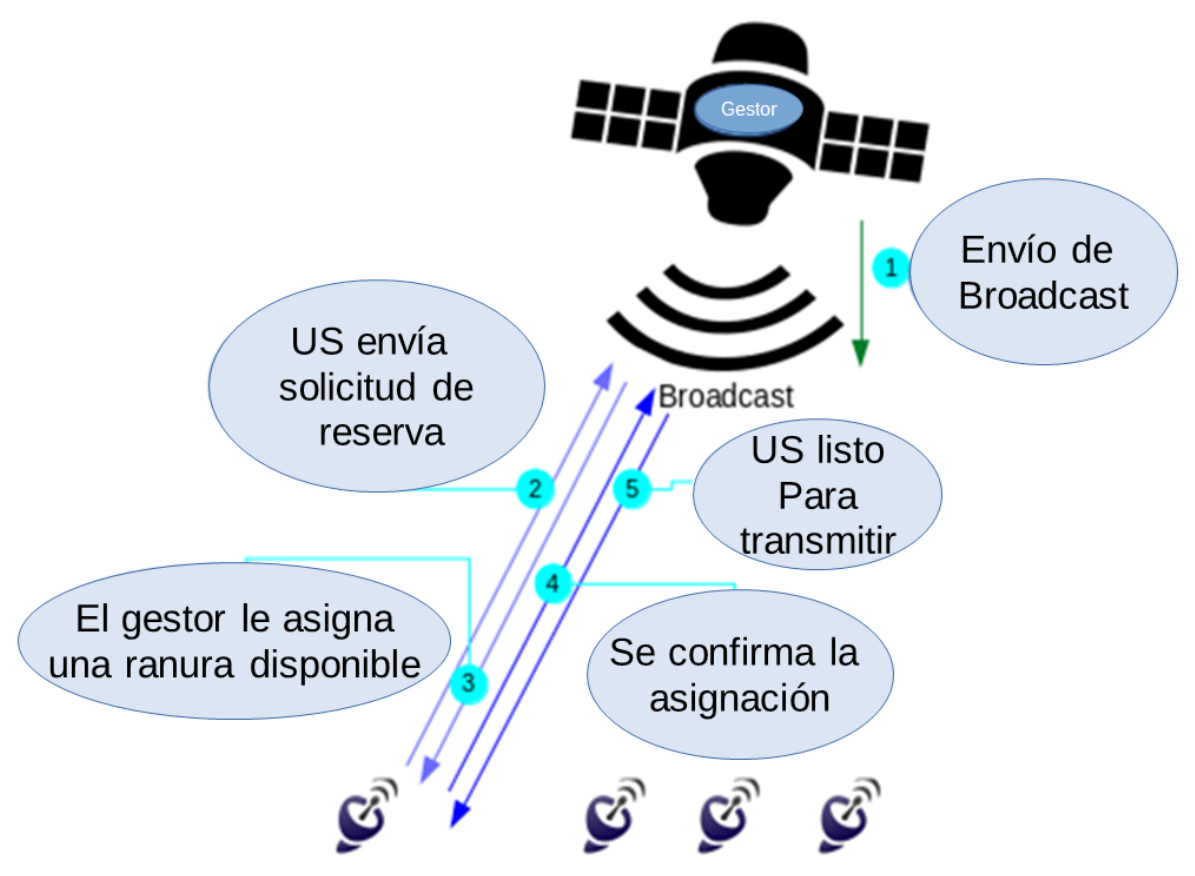

US-1 


\section{Buffer 1 de reservación secundaria, escucha las peticiones de las estaciones}

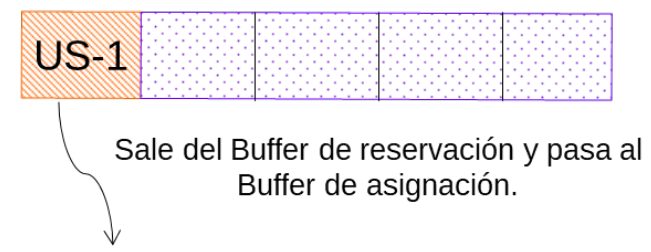

Buffer 2 de asignación secundaria, se van asignando las ranuras disponibles conforme se van solicitando en el Buffer 1.
US solicitando una ranura

Espacio disponible en Buffer 1

Ranuras asignadas a un US

Ranuras asignadas a UP

Ranuras disponibles para asignar a US en Buffer 2

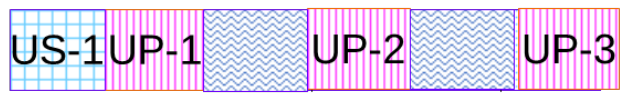

Figura 17. Estaciones secundarias escuchando broadcast, y US-1 pidiendo reservación y asignación de espacio.

Una vez que los huecos han sido llenados, el gestor sigue enviando el broadcast pero avisa que no hay espacios disponibles, y si hay US queriendo reservar, deberán entrar a una fila de espera y aguardar hasta que se cuente con un espacio libre. Observe la Figura 18.

Los huecos se asignan de acuerdo a la información que tiene el gestor y si algún US requiere de más espacio, éste deberá volver a pedir una nueva reservación para poder seguir transmitiendo, por lo tanto, deberá hacer nuevamente todo el proceso para reservar.

El broadcast con la información, debe enviarse cada cierto tiempo para que los US que se vayan integrando sepan qué espacios están siendo utilizados y cuáles se encuentran libres, por ende, las estaciones secundarias deben contar con un tiempo de 
espera suficiente, mas no extensivo, por si no llega a escuchar el broadcast que está mandando el satélite, la estación secundaria se apague o levante una bandera de fallo.

Una vez mandado el broadcast, se deben esperar (aproximadamente) $120 \mathrm{~ms}$ para que la señal llegue a las estaciones terrenas, tiempo mismo que tarda en llegar el mensaje de una estación terrena al satélite, además, se debe añadir un tiempo de procesamiento tanto en las estaciones terrenas como en el satélite, ya que una vez que se detecta el broadcast en la estación terrena, ésta debe saber si requiere de un espacio en el transpondedor para así mandar la solicitud de reserva. En la Figura 19 se muestra el diagrama de flujo del algoritmo de reservación propuesto.

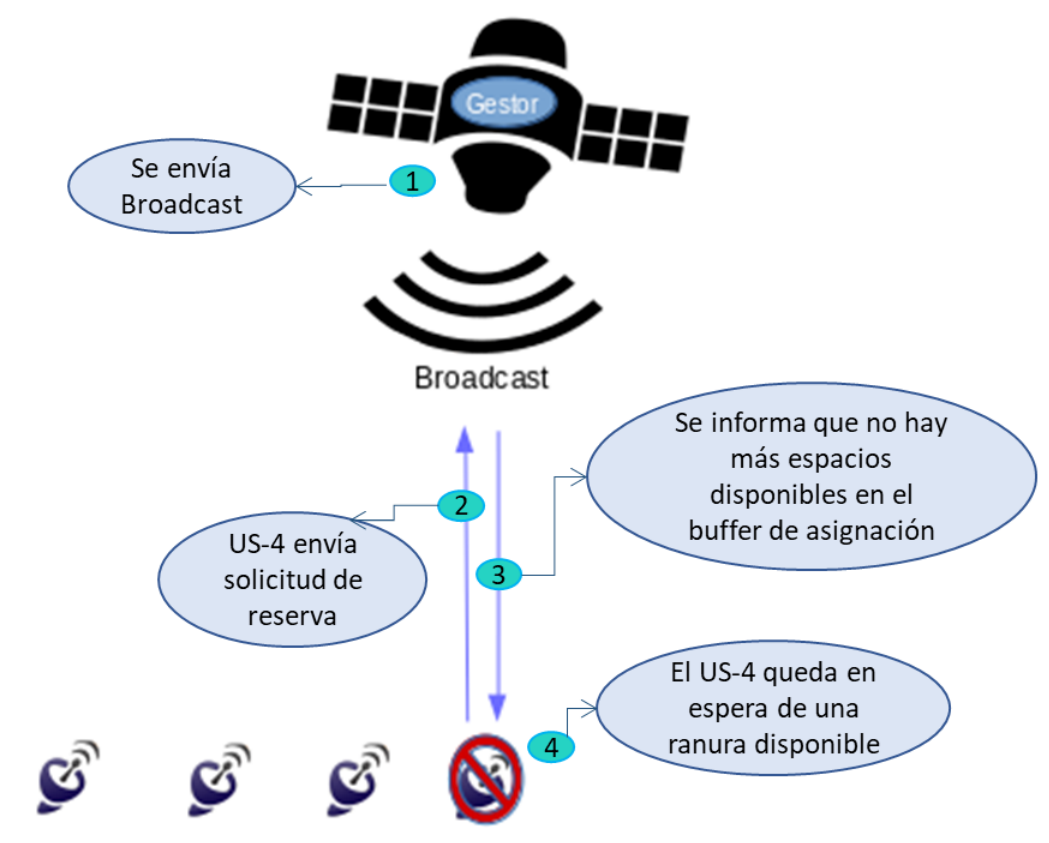

US-1 US-2 US-3 US-4 


\section{Buffer 1 de reservación secundaria, escucha las peticiones de las estaciones}

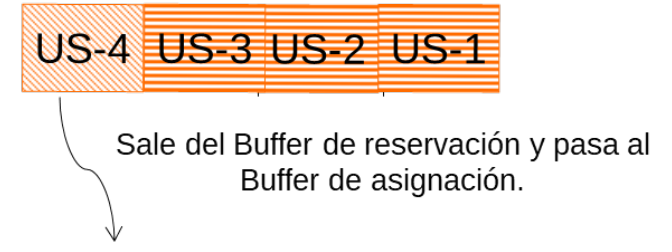

Buffer 2 de asignación secundaria, se van asignando las ranuras disponibles conforme se van solicitando en el Buffer 1.
US solicitando una ranura US que ya ha sigo asignado Ranuras asignadas a un US Ranuras asignadas a UP US-1 UP-1 US-2 UP-2 US-3UP-3

Figura 18. US-4 en espera de reservación.

En caso de que un UP quiera reservar pero no hay ranuras disponibles para los UP, el gestor será el encargado de realizar el monitoreo de las ranuras asignadas y así decidir por medio de funciones cognitivas, qué ranura debe asignarse al UP aún cuando éstas ya fueron reservadas por algún US, ya que siempre que un UP requiera de reservación, debe encontrase un espacio para éste debido a que el UP tiene prioridad. El gestor también es el encargado de suspender la transmisión del US, para que el UP pueda hacer uso de la ranura que se le asignó. Este escenario se tiene pensado en caso de que por alguna emergencia un UP haga una solicitud extraordinaria. La Figura 20 muestra los pasos que se realizan en dicho proceso y la Figura 21 muestra cómo se ve el llenado de los buffers en este caso. 


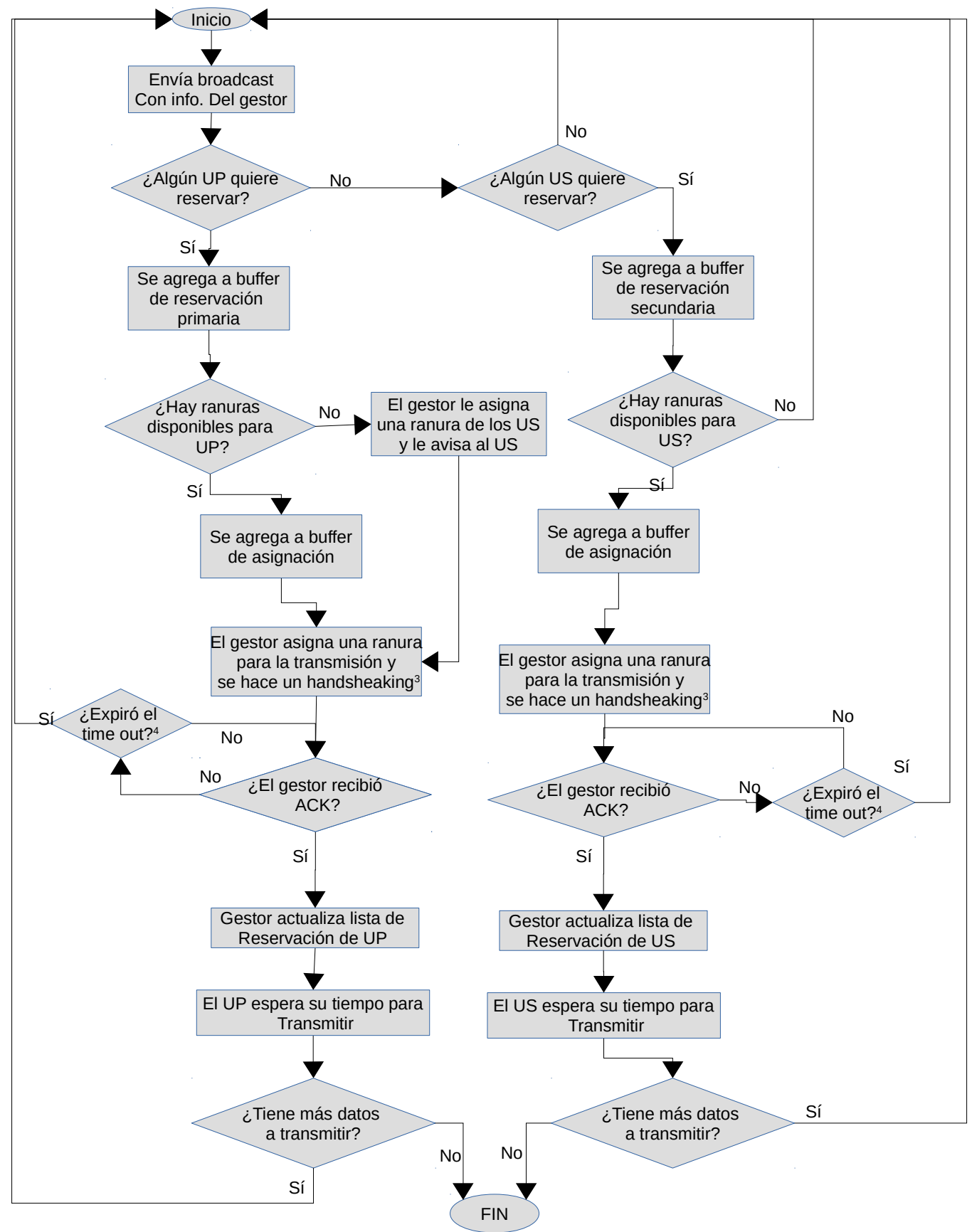

Figura 19. Diagrama de flujo de algoritmo para reservación

3 Time out correspondiente al valor RTT

4 Handshaking entiéndase como el protocolo de inicio de conexión. 


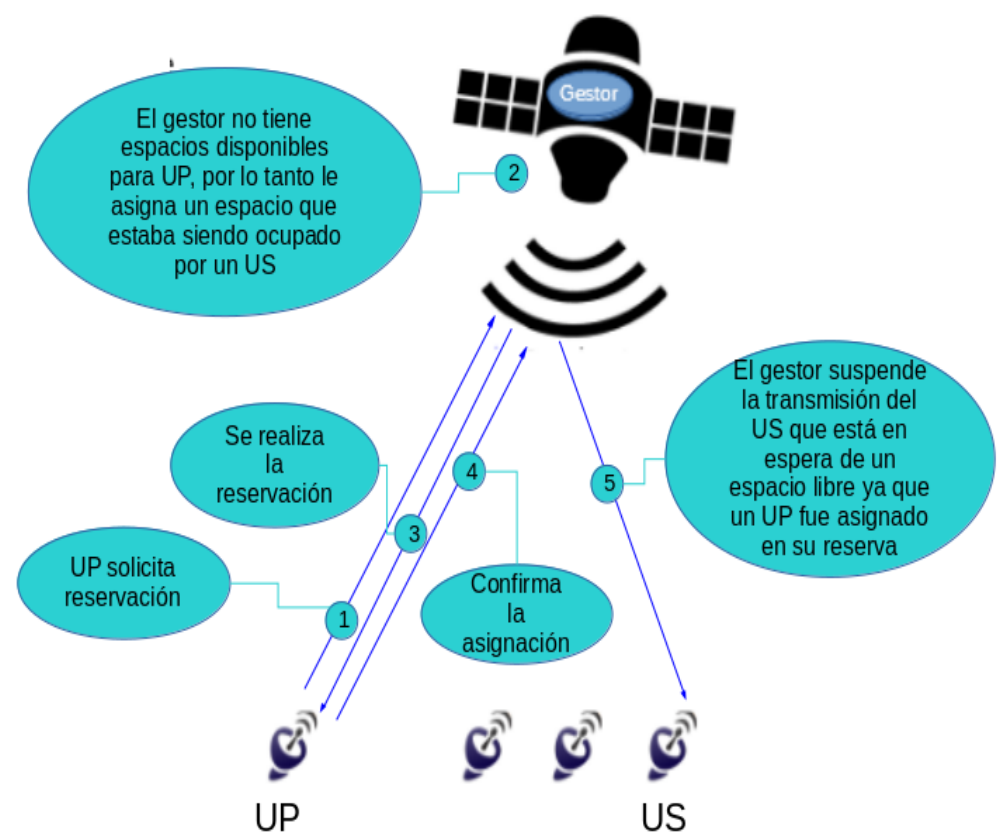

Figura 20. Asignación de espacio a UP en espacios reservados por US.

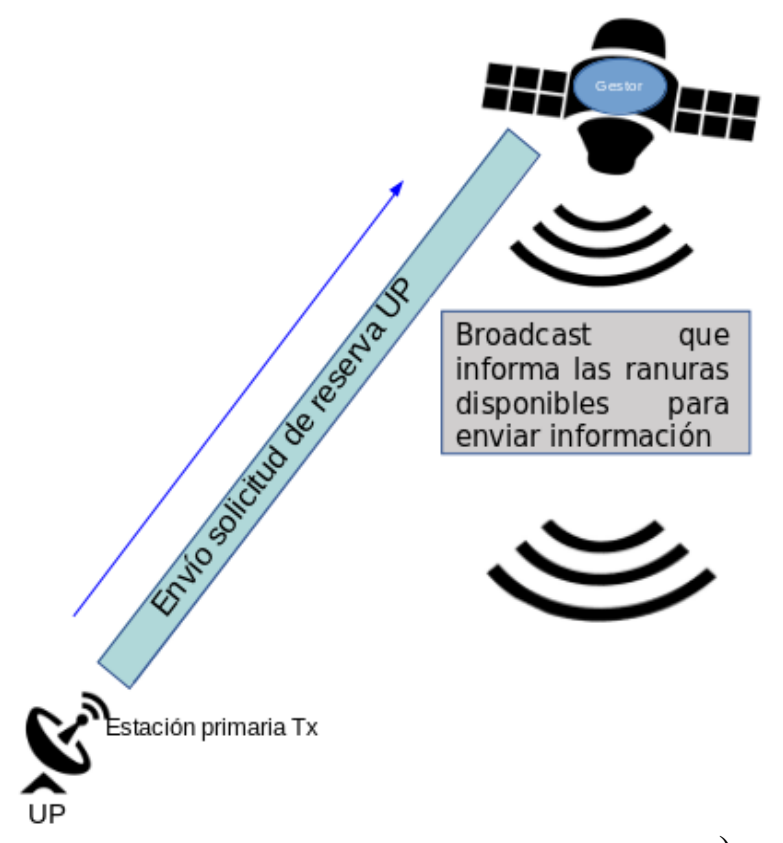

Buffer 1 de reservación primaria, escucha las peticiones de las estaciones

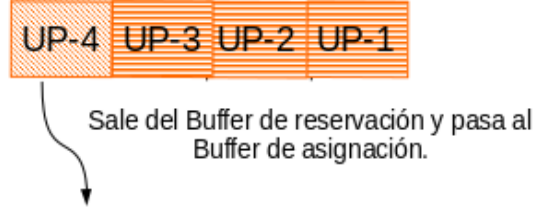

Buffer 2 de asignación se encuentra lleno.

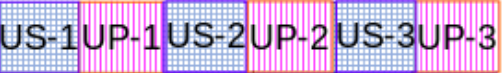

US solicitando una ranura US que ya ha sigo asignado Ranuras asignadas a un US

Ranuras asignadas a UP

a) 


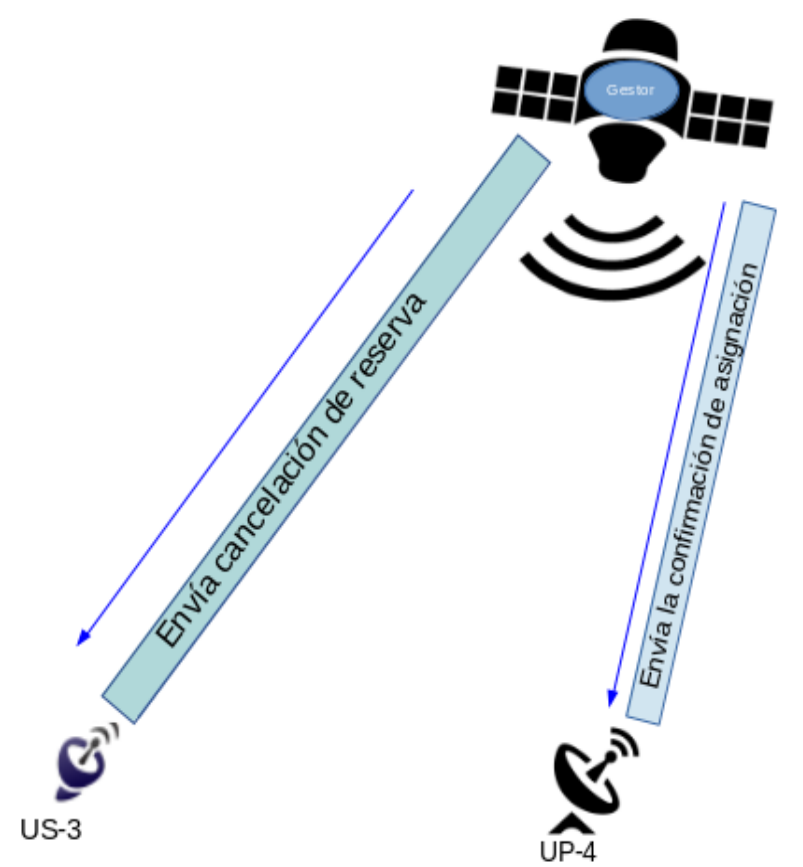

Buffer 1 de reservación primaria, escucha las peticiones de las estaciones

UP-4 UP-3 UP-2 UP-1

Sale del Buffer de reservación y pasa al Buffer de asignación.

Buffer 2 de asignación quita al US-3 y asigna al UP-4.

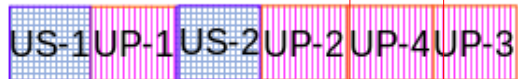

US solicitando una ranura

US que ya ha sigo asignado

Ranuras asignadas a un US

Ranuras asignadas a UP

b)

Figura 21. a) Solicitud de reserva de un UP cuando todos los transpondedores están asignados, b) Asignación de ranura a UP quitando a US.

El gestor también necesita un tiempo para actualizar sus datos y saber qué huecos existen y cuáles ya están reservados. Por lo tanto, en la Ecuación 12, se muestra el tiempo que debe esperar el satélite para enviar nuevamente el mensaje de broadcast.

$$
\begin{gathered}
T_{\text {actualización de broadcast }}=T_{\text {bajada de broadcast }}+T_{\text {petición de reserva }}+T_{\text {proc-sat }}+T_{\text {proc-station }} \\
\mathrm{T}_{\text {actualización de broadcast }}=120 \mathrm{~ms}+120 \mathrm{~ms}+60 \mathrm{~ms}+60 \mathrm{~ms} \\
\mathrm{~T}_{\text {actualización de broadcast }}=360 \mathrm{~ms}
\end{gathered}
$$


En donde $\mathrm{T}_{\text {bajada de broadcast }}$ es el tiempo del enlace de bajada, $\mathrm{T}_{\text {petición de reserva }}$ es el tiempo del enlace de subida, $\mathrm{T}_{\text {proc-sat }}$ es el tiempo de procesamiento en el satélite y $\mathrm{T}_{\text {proc-station }}$ se refiere al tiempo de procesamiento en la estación terrena. Se supone $\mathrm{T}_{\text {proc-sat }}=\mathrm{T}_{\text {proc-station }}=$ $60 \mathrm{~ms}$.

Las simulaciones del tráfico primario se hace con un número aleatorio, con distribución normal, que decide qué porcentaje de ocupación tendrá cada UP para completar el porcentaje requerido $(12 \%, 28 \%$ o $72 \%)$, el US transmisor es informado sobre un espacio libre por medio del broadcast que envía el gestor y pide la reservación de un espacio, llegado su momento, éste comienza la comunicación con el US receptor, al terminar su tiempo asignado debe dejar de transmitir y en caso de querer volver a transmitir, deberá realizar nuevamente el proceso de reservación.

Se harán pruebas aumentando el número de UP y US, recordando que las estaciones trabajan bajo el esquema de reservación. La propuesta es independiente de la frecuencia de transmisión, siempre y cuando se trate de una satélite geoestacionario, por las ventajas que se mencionan en el Capítulo 3, además, se harán variaciones en el tamaño de los paquetes del tráfico enviado.

Por otro lado, se proponen ciertas características del enlace para la simulación las cuales se observan en la Tabla 6. 
Tabla 6. Características del enlace satelital para la simulación

\begin{tabular}{|l|l|}
\hline \multicolumn{2}{|c|}{ Características del enlace satelital } \\
\hline Tipo de satélite & Geoestacionario $(\approx 36000 \mathrm{~km})$ \\
\hline Velocidad de transmisión & $1 \mathrm{Mbps}$ \\
\hline Tipo de tráfico & CBR \\
\hline Ocupación porcentual de UP & $12 \%-28 \%-72 \%$ \\
\hline Tiempo de simulación & $50 \mathrm{~s}$ \\
\hline Tamaño de paquete & $500 \mathrm{~B}, 1000 \mathrm{~B}$ y 1500B \\
\hline Número de UP y US & Varía entre 1 y 15 usuarios \\
\hline
\end{tabular}




\section{Capítulo 6. Resultados}

Una vez hechas las simulaciones, analizamos los archivos de salida y con el script del throughput se sabe el rendimiento de la comunicación (ver ANEXO A.).

En la Figura 22 se muestra el throughput de los UP haciendo uso del $72 \%$ del transpondedor, es decir, deja libre un $28 \%$ del transpondedor que puede ser utilizado por los US como se muestra en el ejemplo de la Figura 23, en donde se muestra a ambos usuarios UP y US, conviviendo en un mismo espacio, en tiempos diferentes.

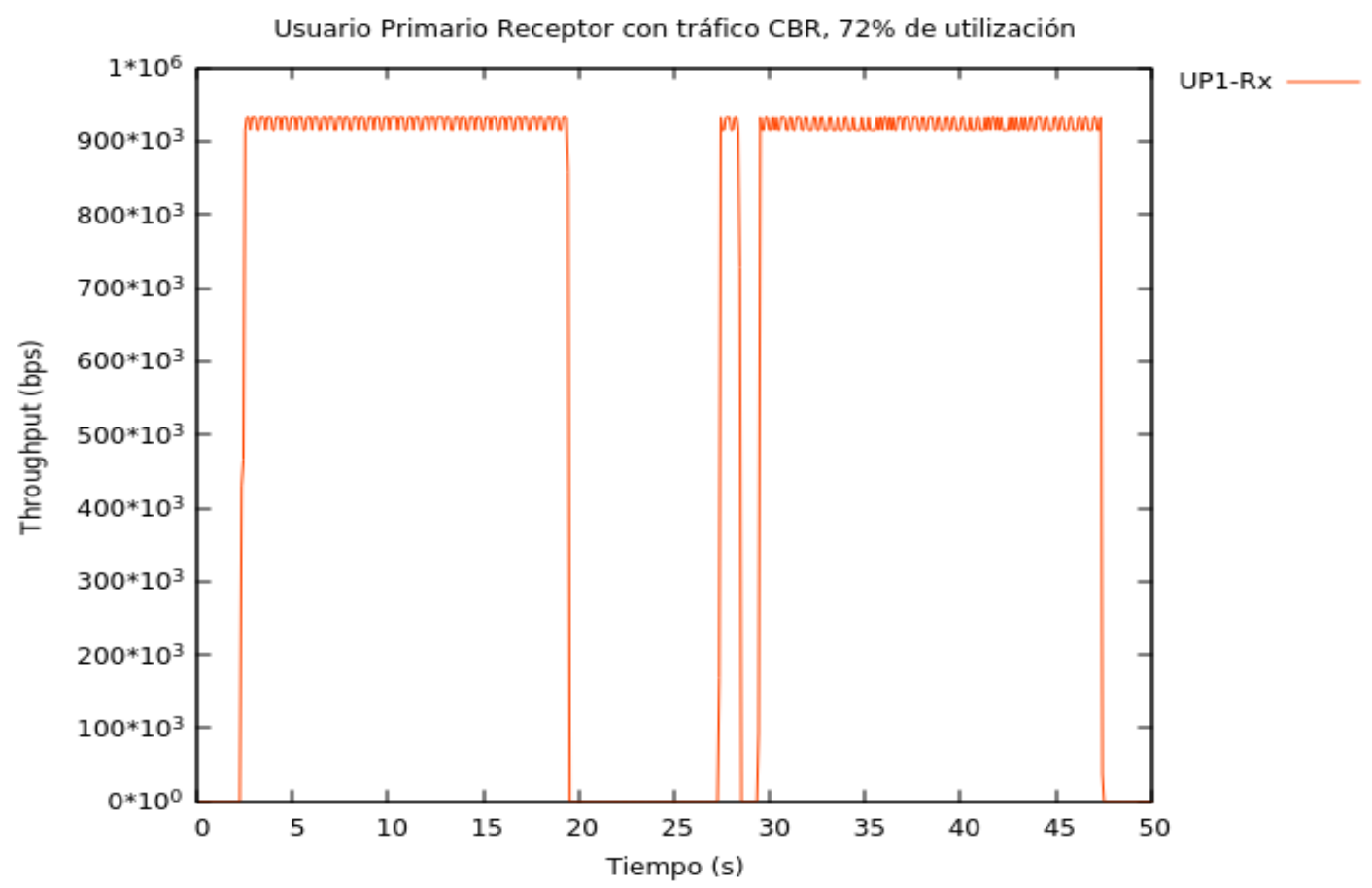

Figura 22. Throughput medido en la estación receptora del UP haciendo uso del 72\% del transpondedor. 


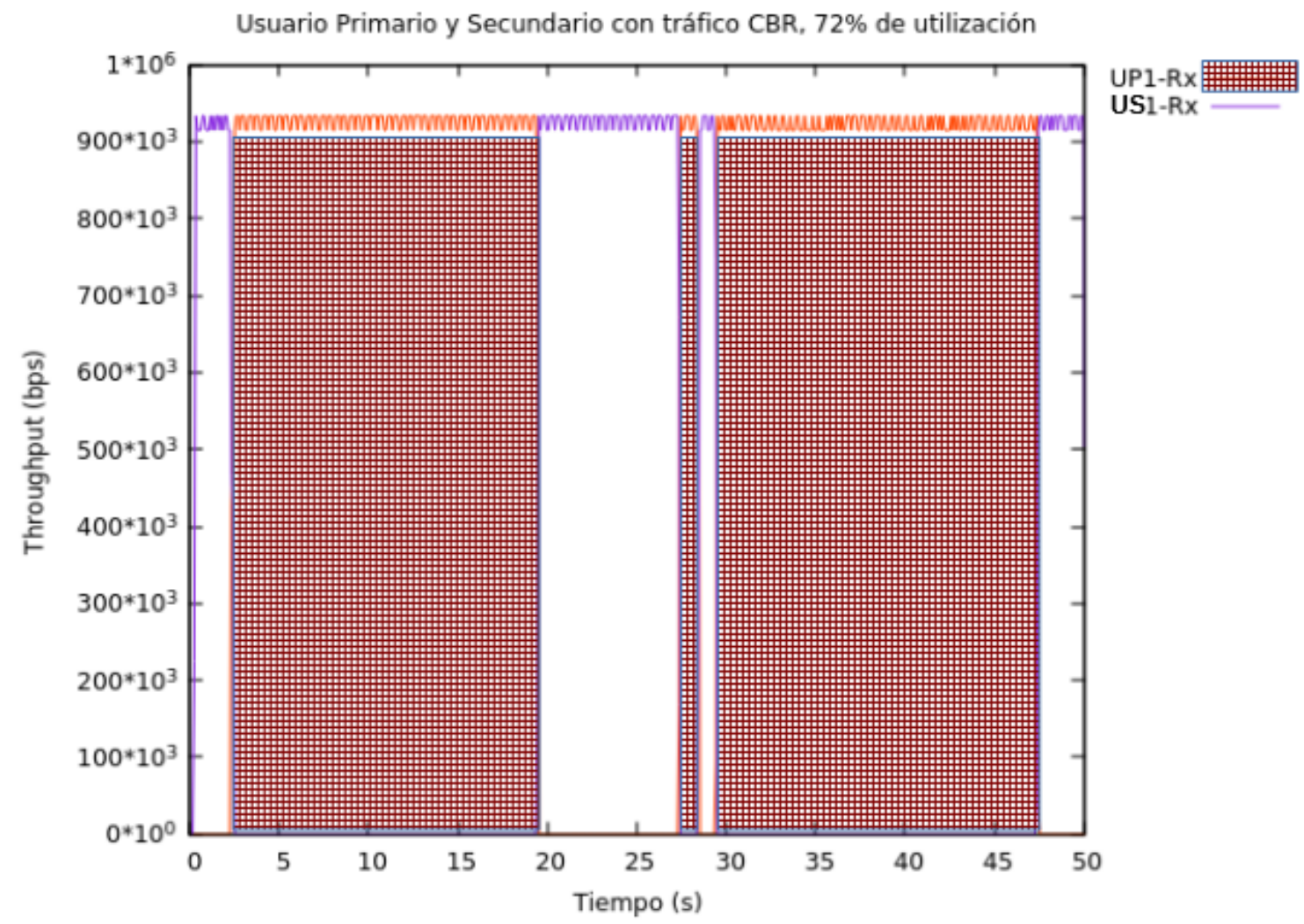

Figura 23. Throughput medido en la estación receptora del UP y del US haciendo uso del $72 \%$ del transpondedor por parte del UP.

En la Figura 24 se muestra el resultado de un escenario que cuenta con 5 estaciones primarias y 10 estaciones secundarias, para este ejemplo la ocupación de los UP es del 12\%. Los UP se muestran con líneas anaranjadas y fondo a cuadros y los US con líneas verdes sin fondo. Podemos observar que se alcanza un promedio del 93\% de rendimiento en la comunicación, hay que recordar que se utiliza tráfico CBR y el tamaño 
de los paquetes es de 500 bytes.

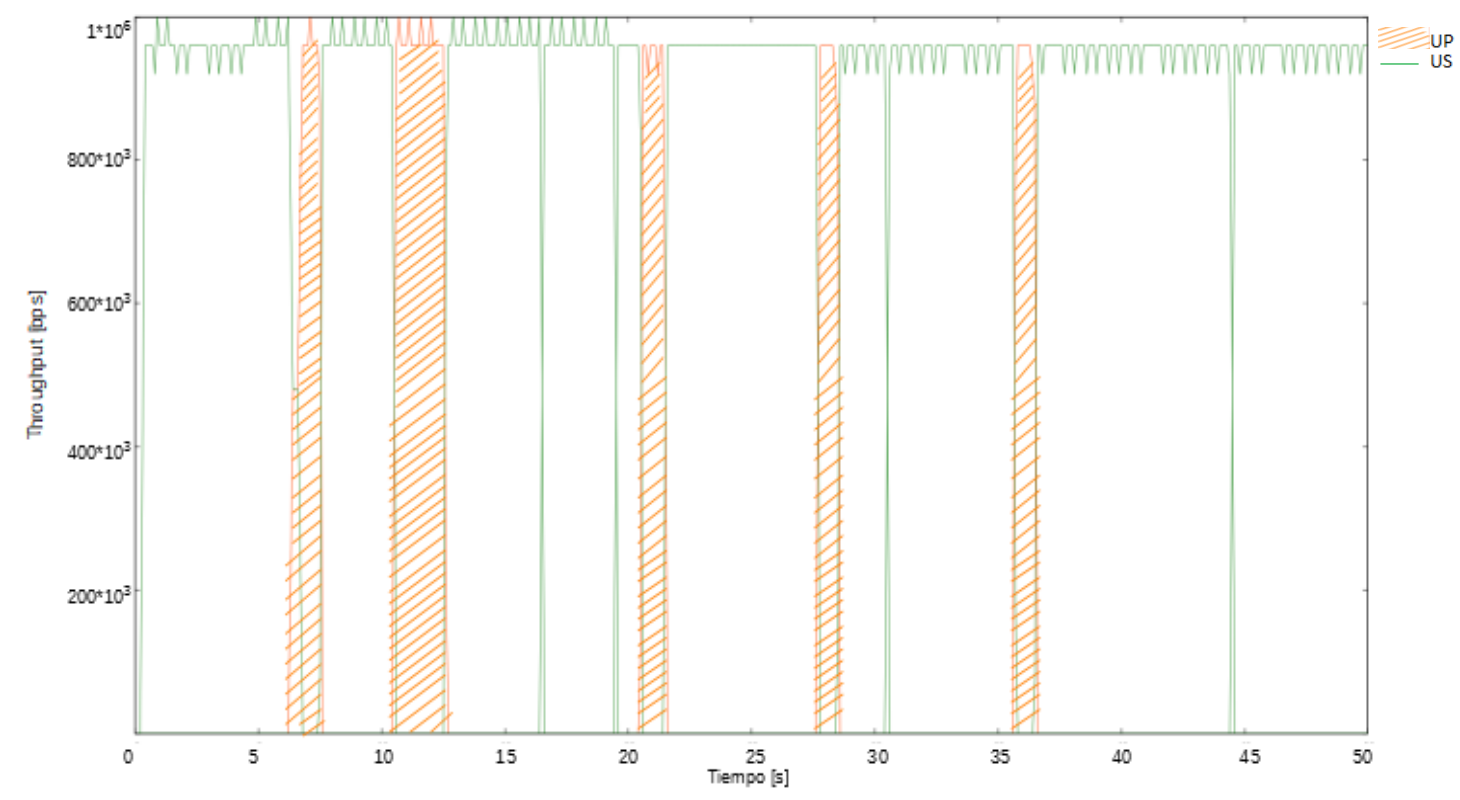

Figura 24. Throughput medido en las estaciones receptoras de los 5 UP y 10 US, se hace uso del $12 \%$ del transpondedor por parte de los UP, paquetes de 500 bytes.

Se hicieron diferentes simulaciones para obtener el thoughput, variando el número de UP, US, ocupación y tamaño de paquetes. Se observaron diferentes comportamientos y resultados, los cuales se observan en la Tabla 7. 
Tabla 7. Resultados de las simulaciones variando UP, US, ocupación y tamaño de los paquetes.

\begin{tabular}{|c|c|c|c|c|c|c|}
\hline \# prueba & UP & US & $\begin{array}{l}\text { Ocupación } \\
\text { primaria } \\
(\%)\end{array}$ & \begin{tabular}{|c|} 
Tamaño \\
de \\
paquetes \\
(Bytes)
\end{tabular} & $\begin{array}{l}\text { Throughput } \\
\text { promedio } \\
(\%)\end{array}$ & Observaciones \\
\hline 1 & 5 & 10 & 12 & 500 & 93 & $\begin{array}{c}\text { Presenta picos que alcanzan } \\
\text { hasta el } 100 \% \text { de } \\
\text { rendimiento. }\end{array}$ \\
\hline 2 & 5 & 10 & 12 & 1000 & 95 & $\begin{array}{l}\text { Se presenta un rendimiento } \\
\text { con menos fluctuaciones. }\end{array}$ \\
\hline 3 & 4 & 10 & 12 & 1500 & 97 & $\begin{array}{c}\text { Presenta tiempos que } \\
\text { alcanzan hasta el } 100 \% \text { de } \\
\text { rendimiento, pero se } \\
\text { presentan menos cambios } \\
\text { que la prueba } 1 .\end{array}$ \\
\hline 4 & 7 & 10 & 28 & 500 & 93 & $\begin{array}{c}\text { Presenta picos que alcanzan } \\
\text { hasta el } 100 \% \text { de } \\
\text { rendimiento. }\end{array}$ \\
\hline 5 & 7 & 10 & 28 & 1000 & 97 & $\begin{array}{c}\text { Se presenta un rendimiento } \\
\text { con menos fluctuaciones que } \\
\text { la prueba } 4 .\end{array}$ \\
\hline 6 & 6 & 10 & 28 & 1500 & 97 & $\begin{array}{c}\text { Se presenta un rendimiento } \\
\text { con menos fluctuaciones que } \\
\text { la prueba } 5 .\end{array}$ \\
\hline 7 & 9 & 10 & 72 & 500 & 93 & $\begin{array}{c}\text { Presenta picos que alcanzan } \\
\text { hasta el } 100 \% \text { de } \\
\text { rendimiento. }\end{array}$ \\
\hline 8 & 9 & 10 & 72 & 1000 & 98 & $\begin{array}{l}\text { El rendimiento es mucho más } \\
\text { estable que la prueba } 7 .\end{array}$ \\
\hline 9 & 9 & 10 & 72 & 1500 & 98 & $\begin{array}{c}\text { Tiene más variaciones que la } \\
\text { prueba } 8, \text { sin embargo, hay } \\
\text { tiempos en los que se } \\
\text { alcanza el } 100 \% \text { de } \\
\text { rendimiento. }\end{array}$ \\
\hline 10 & 5 & 20 & 12 & 500 & 93 & $\begin{array}{c}\text { Presenta picos que alcanzan } \\
\text { hasta el } 100 \% \text { de } \\
\text { rendimiento. }\end{array}$ \\
\hline 11 & 5 & 20 & 12 & 1000 & 97 & $\begin{array}{l}\text { Presenta menos picos que la } \\
\text { prueba } 10 \text {, es más estable. }\end{array}$ \\
\hline 12 & 5 & 20 & 12 & 1500 & 97 & $\begin{array}{c}\text { Presenta mayor estabilidad } \\
\text { que la prueba } 11, \text { llega a } \\
\text { alcanzar un } 100 \% \text { de } \\
\text { rendimiento. }\end{array}$ \\
\hline 13 & 7 & 20 & 28 & 500 & 93 & $\begin{array}{c}\text { Presenta picos que alcanzan } \\
\text { hasta el } 100 \% \text { de } \\
\text { rendimiento. }\end{array}$ \\
\hline 14 & 11 & 20 & 28 & 1000 & 95 & $\begin{array}{c}\text { Se presenta un rendimiento } \\
\text { con menos fluctuaciones que } \\
\text { la prueba } 1 .\end{array}$ \\
\hline 15 & 10 & 20 & 28 & 1500 & 97 & $\begin{array}{c}\text { Presenta mayor estabilidad } \\
\text { que la prueba } 14, \text { Ilega a } \\
\text { alcanzar un } 100 \% \text { de } \\
\text { rendimiento. }\end{array}$ \\
\hline
\end{tabular}


En las Figuras 25, 26 y 27, se muestra el resultado de cómo al ir aumentado el número de usuarios secundarios, se va saturando el espacio libre que dejan los usuarios primarios, es decir, si los usuarios primarios utilizan el $12 \%$ del total del tiempo para transmitir, dejan libre $88 \%$ de este espacio para que los usuarios secundarios puedan utilizarlo, en donde el $88 \%$ corresponde al $100 \%$ de ocupación de los usuarios secundarios. Por lo tanto, se observa en la simulación, cuantos usuarios secundarios se pueden utilizar como máximo antes de saturar el espacio de los usuarios secundarios variando el tamaño de los paquetes y la ocupación de los UP.

\section{Variación de usuarios con 500B}

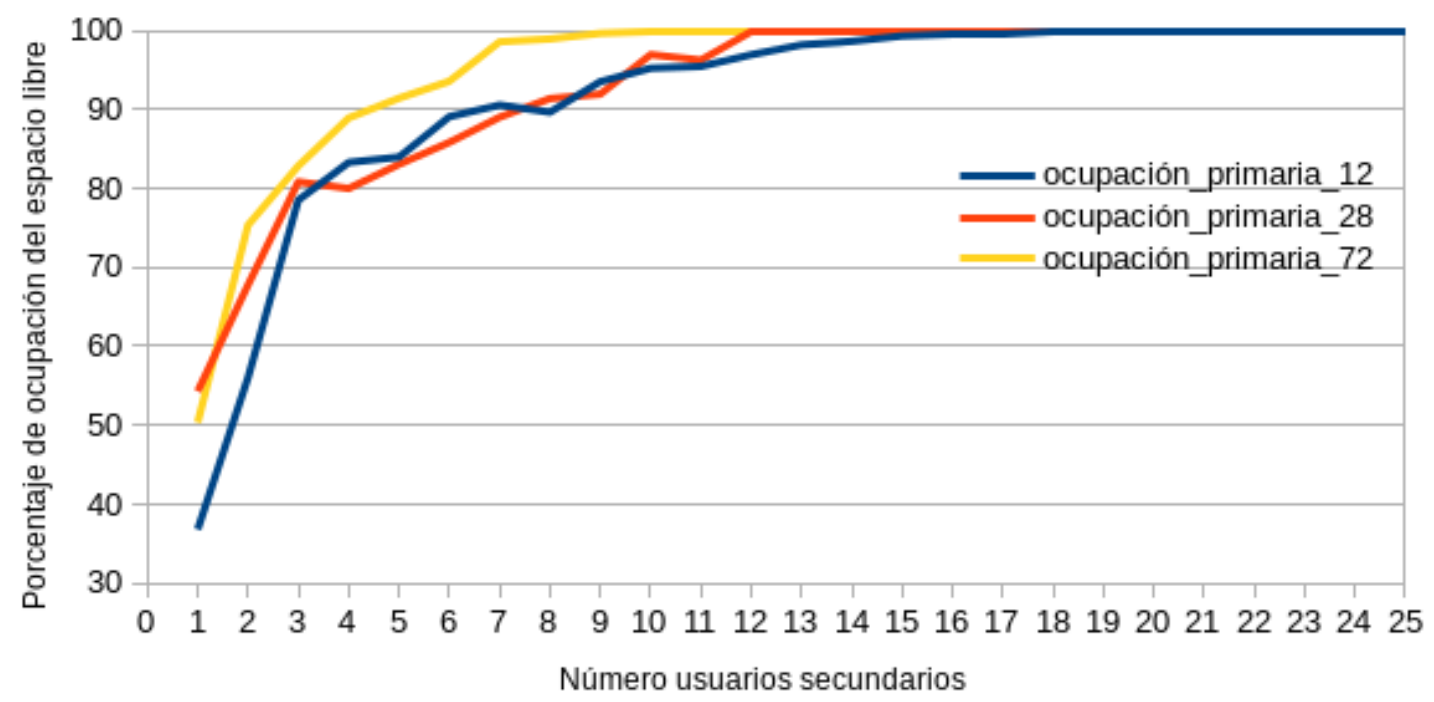

Figura 25. Número máximo de usuarios secundarios para las diferentes ocupaciones con paquetes de 500B. 
Variación de usuarios con 1000B

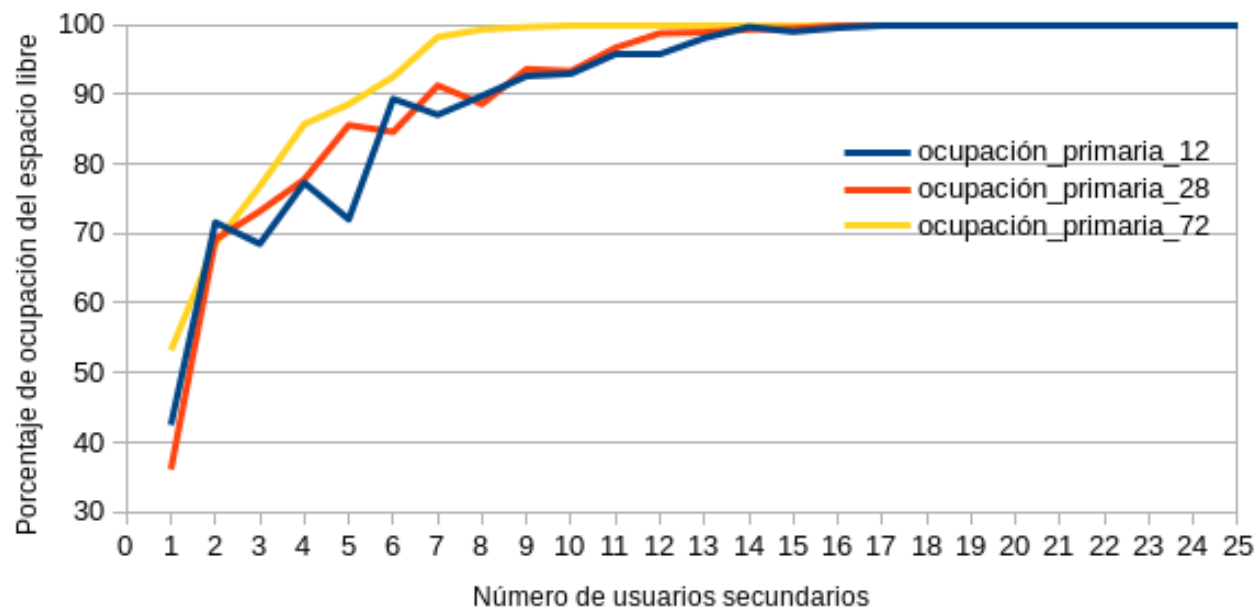

Figura 26. Número máximo de usuarios secundarios para las diferentes ocupaciones con paquetes de 1000B.

Variación de usuarios con 1500B

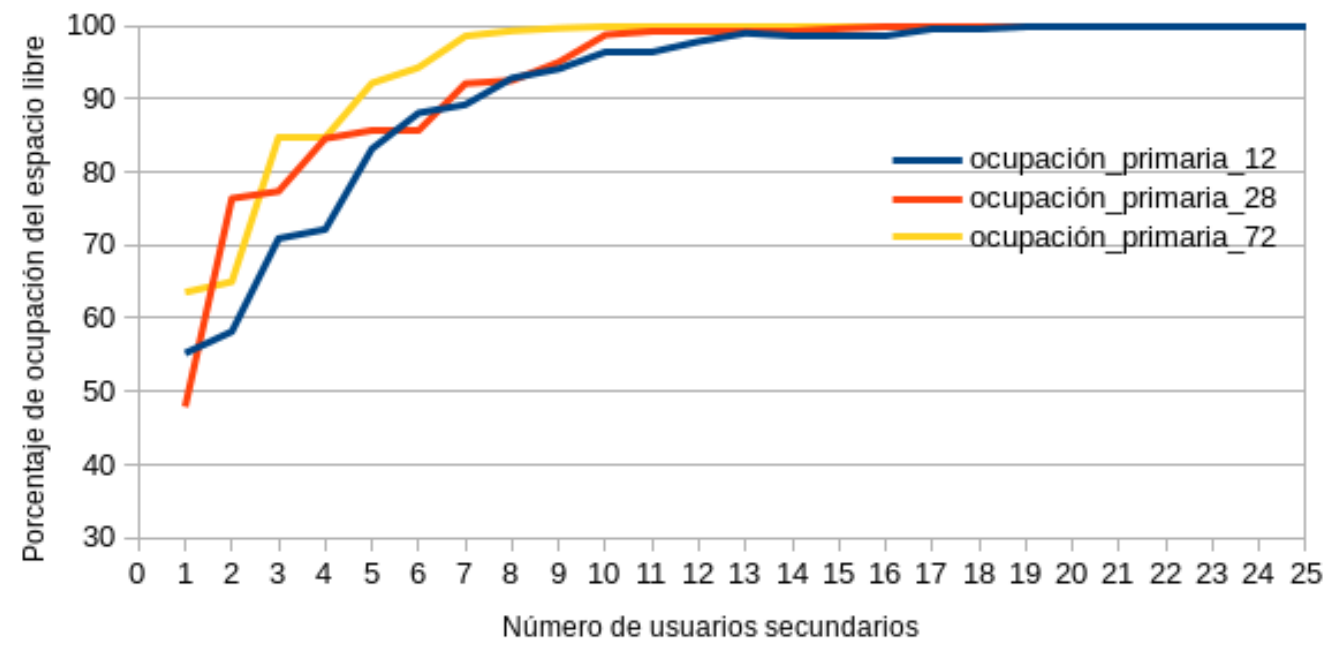

Figura 27. Número máximo de usuarios secundarios para las diferentes ocupaciones con paquetes de 1500B. 
En las Figuras 28, 29 y 30 se muestra cómo varía el porcentaje de ocupación libre de los US si se varía el tamaño de los paquetes entre 500B, 1000B y 1500B, esto para cada una de las ocupaciones primarias con las que se ha trabajado $(12 \%, 28 \%$ y $72 \%)$.

12\% de Ocupación primaria. Variación de US 500B, 1000B y 1500B

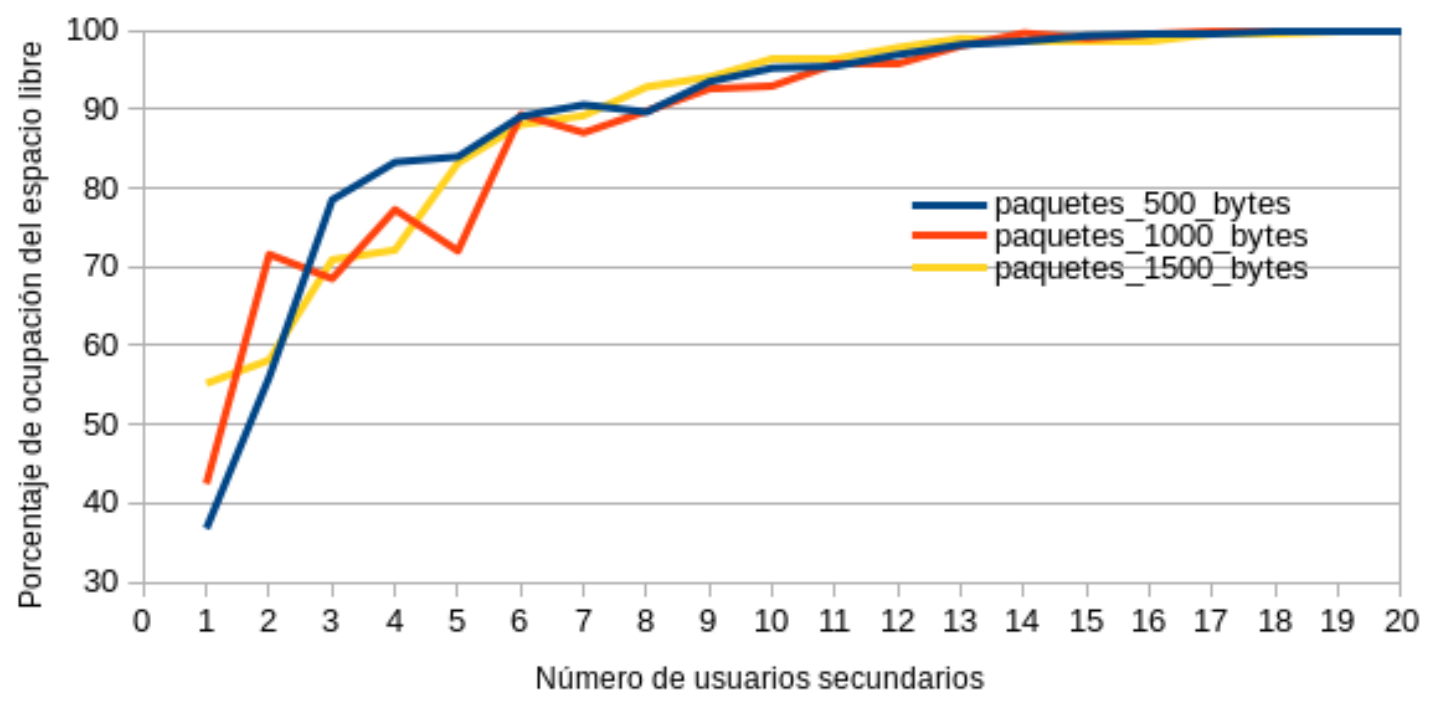

Figura 28. Porcentaje de ocupación para diferentes número de US, variando el tamaño de los paquetes, porcentaje de ocupación primaria $12 \%$. 
28\% de Ocupación primaria. Variación de US 500B, 1000B y 1500B

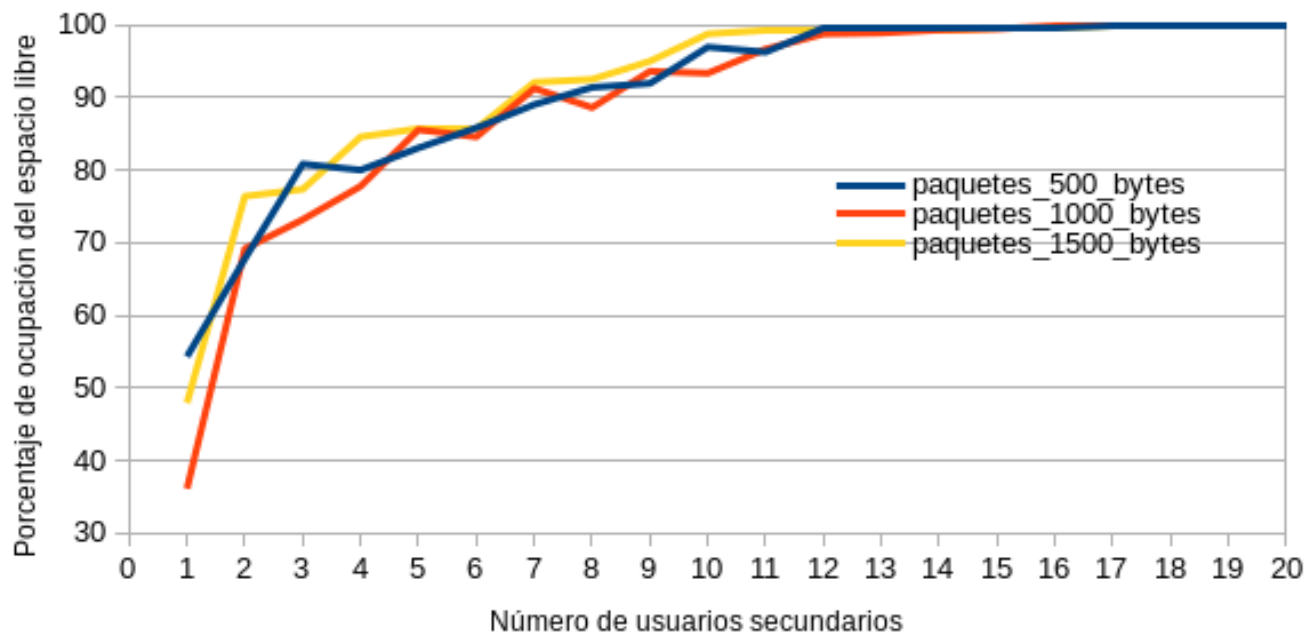

Figura 29. Porcentaje de ocupación para diferentes número de US, variando el tamaño de los paquetes, porcentaje de ocupación primaria $28 \%$.

72\% de Ocupación primaria. Variación de US 500B, 1000B y 1500B

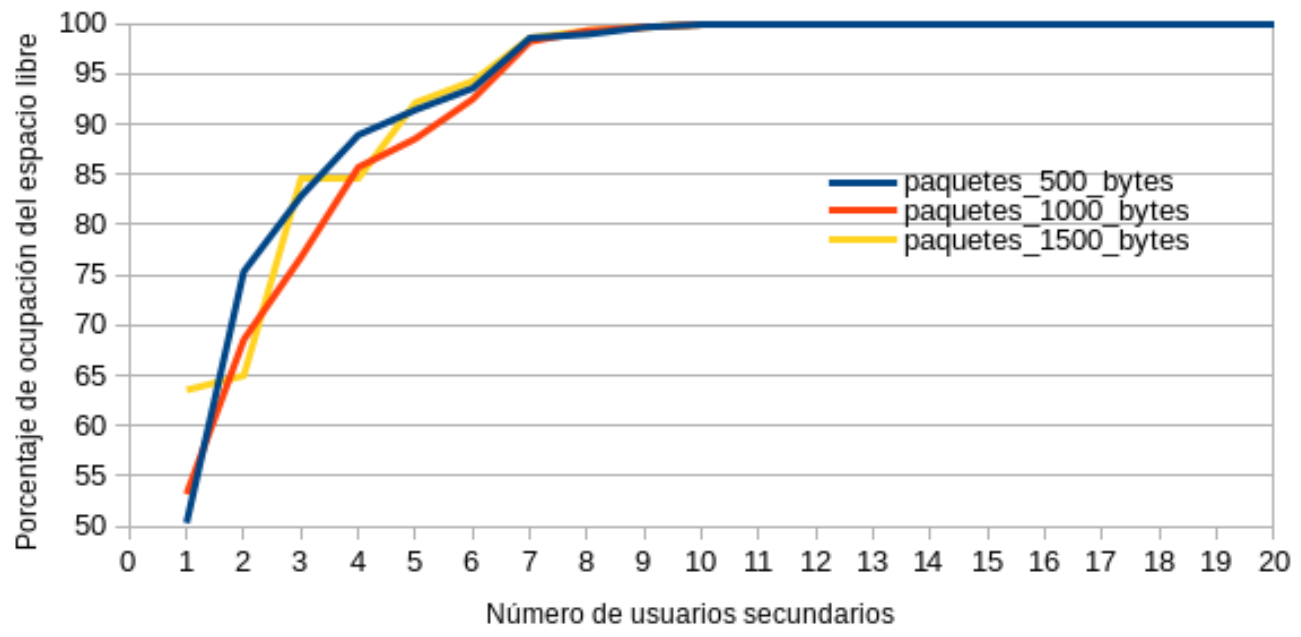

Figura 30. Porcentaje de ocupación para diferentes número de US, variando el tamaño de los paquetes, porcentaje de ocupación primaria $72 \%$. 
Cabe mencionar que se muestran los ejemplos más significativos del total de simulaciones realizadas, se observó que mientras más grande sea el tamaño de paquete, el rendimiento muestra una mejora en cuanto a estabilidad. Por otro lado, se encontró que el máximo número de US es de 15, para una ocupación por parte de los UP del 12\%, 12 US para una ocupación primaria del 28\% y 9 US para una ocupación de los UP del $72 \%$. 


\section{Capítulo 7. Conclusiones}

En este trabajo de investigación, se propone un método para la utilización del espectro satelital basado en acceso al medio por reservación TDMA/DAMA, donde se incorporan funciones de radios cognitivos para el caso de la ocupación inesperada por parte de los usuarios primarios que consiste en movilidad reactiva anulando la comunicación secundaria en presencia de una solicitud inesperada de un usuario primario.

Con base en la investigación, se tienen datos estadísticos tomados de la literatura que se replicaron con simulaciones para caracterizar que el espectro radio eléctrico en las comunicaciones satelitales está siendo subutilizado. Tomando en consideración las simulaciones realizadas, podemos observar que los usuarios primarios y usuarios secundarios pueden convivir en un mismo entorno operando con el algoritmo propuesto.

Se encontró que el máximo número de usuarios para la ocupación del $72 \%$ por parte de los usuarios primarios es de 9 usuarios secundarios. Suponiendo que el $28 \%$ de la ocupación está definida para los US, una vez que este porcentaje de ocupación se encuentra lleno y si existiera alguna solicitud extraordinaria por parte de algún UP, el gestor mediante funciones cognitivas, deberá quitar de la asignación a un US o suspender la transmisión de éste para hacer la reasignación al UP. 


\section{Capítulo 8. Trabajo a futuro}

Este trabajo de investigación abre diferentes caminos para continuar en el tema de los radios cognitivos y los enlaces satelitales, a través de la propuesta realizada, un siguiente paso es proponer un sistema que no sea centralizado y que sea proactivo para generar soluciones con base en el conocimiento que se va obteniendo del entorno y así, poder emplear dicho sistema en las comunicaciones satelitales actuales.

Otra propuesta es hacer dinámico el gestor y se pueda distribuir en diferentes frecuencias que no afecte el funcionamiento del transpondedor, para no tener un gestor centralizado. 


\section{Referencias}

[1] C. Hemández, L. Pedraza, I. Páez, y E. Rodriguez-Colina, “Análisis de la Movilidad Espectral en Redes de Radio Cognitiva”, Inf. tecnológica, vol. 26, núm. 6, pp. 169-186, 2015.

[2] K. Seifu y C. T. Law, "Communication Satellites: Frequency Band limitations Versus Implementations”, Idc-Online.Com, pp. 1-8.

[3] DIRECCIÓN DE COMUNICACIÓN DE HISPASAT y DISEÑO, "Informe anual 2010", MAdrid, 2010.

[4] HISPASAT, "Ocupación del sistema", 2014. [En línea]. Disponible en: http://www.hispasat.com/es/informe-anual-2014/ocupacion-del-sistema.html. [Consultado: 16-ago-2016].

[5] SES, "SES YTD and Q3 2015 Results", 2015. [En línea]. Disponible en: http://www.spaceref.com/news/viewpr.html?pid=47203. [Consultado: 31 -ago2016].

[6] Eutelsat, "Resultados del periodo 2015-2016 de Eutelsat", 2016. [En línea]. Disponible en: http://latamsatelital.com/resultados-del-periodo-2015-2016eutelsat/. [Consultado: 05-abr-2016].

[7] G. Maral y M. Bousquet, Satellite communications systems, 5th ed., vol. 40, núm. 6. 2001.

[8] IEEE, "IEEE Standard Definitions of Terms for Antennas", IEEE Commun. Mag., pp. 1-31, 1983.

[9] “Transponders", Jsat international, 2016. [En línea]. Disponible en: http://www.jsati.com/why-satellite-how-spacesegment4.asp. [Consultado: 20-mar2016].

[10] I. F. Akyildiz, Won-Yeol Lee, M. C. Vuran, y S. Mohanty, "A survey on spectrum management in cognitive radio networks", IEEE Commun. Mag., vol. 46, núm. 4, pp. 40-48, abr. 2008. 
[11] J. F. Androlewicz, R. L. Buffington, R. S. Erwin, J. Crane, K. Avery, y J. Lyke, "Software-Defined and Cognitive Radio Technology for Military Space Applications", 2011 Wirel. Innov. Forum Conf. Commun. Technol. Softw. Defin. Radio (SDR'11 - WInnComm), 2011.

[12] I. P. Sabaté, "Implementación de terminales de Radio Cognitiva en la banda de TV”, Universidad Politécnica de Cataluña, 2016.

[13] P. Pawełczak, F. Hoeksema, R. V Prasad, y R. Hekmat, "Dynamic Spectrum Access : An Emergency Network Case Study".

[14] J. Mitola y G. Q. Maguire, "Cognitive radio: making software radios more personal”, IEEE Pers. Commun., vol. 6, núm. 4, pp. 13-18, 1999.

[15] S. Haykin, "Cognitive radio: brain-empowered wireless communications", IEEE J. Sel. Areas Commun., vol. 23, núm. 2, pp. 201-220, feb. 2005.

[16] T. T. Ha, Digital Satellite Communications, Second edi. 1990.

[17] C. Morlet, M.-L. Boucheret, V. Calmettes, B. Paillassa, y T. Perennou, "Towards generic satellite payloads : software radio", en Proceedings International Parallel and Distributed Processing Symposium, 2003, vol. 0, núm. C, p. 7.

[18] B. Paillassa y C. Morlet, "Flexible satellites: Software radio in the sky", 10th Int. Conf. Telecommun. ICT 2003, vol. 2, núm. I, pp. 1596-1600, 2003.

[19] E. Biglieri, "An overview of Cognitive Radio for satellite communications", en 2012 IEEE First AESS European Conference on Satellite Telecommunications (ESTEL), 2012, pp. 1-3.

[20] E. A. Hoyos, H. F. B. Orozco, y G. L. A. Méndez, “Diseño e implementación en FPGA de un modem 16QAM basado en CORDIC para satélites cognitivos”, vol. 2, núm. 51, pp. 181-187, 2012.

[21] H. Luiz et al., "MODEM CORDIC 16QAM en FPGA para Satélites Cognitivos", vol. 9, núm. 97300, pp. 83-89, 2012.

[22] J. E. Volder, "The CORDIC Trigonometric Computing Technique", IEEE Trans. Electron. Comput., vol. EC-8, núm. 3, pp. 330-334, sep. 1959. 
[23] C. Morlet, F. Iacomacci, F. Autelitano, y F. Quaranta, "Reconfigurable implementation for On-Board digital Processors", en 2008 10th International Workshop on Signal Processing for Space Communications, 2008, pp. 1-7.

[24] S. M. Perlaza, E. A. Hoyos, y P. V. Vera, "Reconfigurable Satellite Payload Model based on Software Radio Technologies", ANDESCON, pp. 1-6, 2006.

[25] D. Gozupek, S. Bayhan, y F. Alagoz, "A novel handover protocol to prevent hidden node problem in satellite assisted cognitive radio networks", en 2008 3rd International Symposium on Wireless Pervasive Computing, 2008, pp. 693-696.

[26] S. Maleki, S. Chatzinotas, J. Krause, y K. Liolis, "Cognitive Zone for Broadband Satellite Communication in 17 . 3-17 . 7 GHz Band", IEEE Wirel. Commun., vol. 4, núm. 3, pp. 1-4, 2015.

[27] C. Kourogiorgas, A. D. Panagopoulos, y K. Liolis, "Cognitive uplink FSS and FS links coexistence in Ka-band: Propagation based interference analysis", en 2015 IEEE International Conference on Communication Workshop (ICCW), 2015, pp. 1675-1680.

[28] S. Maleki et al., "Cognitive spectrum utilization in Ka band multibeam satellite communications”, IEEE Commun. Mag., vol. 53, núm. 3, pp. 24-29, mar. 2015.

[29] V. Icolari, D. Tarchi, A. Guidotti, y A. V. Coralli, "Beam pattern allocation strategies for satellite cognitive radio systems", en 2015 IEEE International Conference on Communication Workshop (ICCW), 2015, pp. 1652-1657.

[30] V. Icolari, A. Guidotti, D. Tarchi, y A. Vanelli-Coralli, "An interference estimation technique for Satellite cognitive radio systems", en 2015 IEEE International Conference on Communications (ICC), 2015, vol. 2015-Septe, pp. 892-897.

[31] E. Lagunas, S. K. Sharma, S. Maleki, S. Chatzinotas, y B. Ottersten, "Power Control for Satellite Uplink and Terrestrial Fixed-Service Co-Existence in KaBand", en 2015 IEEE 82nd Vehicular Technology Conference (VTC2015-Fall), 2015, pp. 1-5. 
[32] E. Lagunas, S. Maleki, S. Chatzinotas, M. Soltanalian, A. I. Perez-Neira, y B. Oftersten, "Power and rate allocation in cognitive satellite uplink networks", en 2016 IEEE International Conference on Communications (ICC), 2016, pp. 1-6.

[33] A. Guidotti et al., "Spectrum awareness and exploitation for Cognitive Radio Satellite Communications", en 2015 European Conference on Networks and Communications (EuCNC), 2015, pp. 16-20.

[34] M. Höyhtyä, "Frequency sharing between FSS and BSS satellites in the 17.3-18.4 GHz band", pp. 176-179, 2015.

[35] D. Tarchi et al., "Technical Challenges for Cognitive Radio Application in Satellite Communications", en Proceedings of the 9th International Conference on Cognitive Radio Oriented Wireless Networks, 2014.

[36] S. K. Sharma, S. Chatzinotas, y B. Ottersten, "Cognitive Radio Techniques for Satellite Communication Systems”, en 2013 IEEE 78th Vehicular Technology Conference (VTC Fall), 2013, pp. 1-5.

[37] “Características generales Sistemas y redes de telecomunicaciones por satélite". pp. 1-64.

[38] W. Stallings, Comunicaciones y Redes de Computadores, vol. $7^{\circ}$ Edición, núm. 978-84-205-4110-5. 2004.

[39] IFT, “Cuadro nacional de atribución de frecuencias”, p. 426, 2015.

[40] T. Issariyakul y E. Hossain, Introduction to Network Simulator NS2, Second. Boston, MA: Springer US, 2012.

[41] ns-users, "The Network Simulator: Building Ns". [En línea]. Disponible en: www.isi.edu/nsnam/ns/ns-build.html\#pieces. [Consultado: 17-dic-2017]. 


\section{ANEXO A. Script de Throughput en Perl}

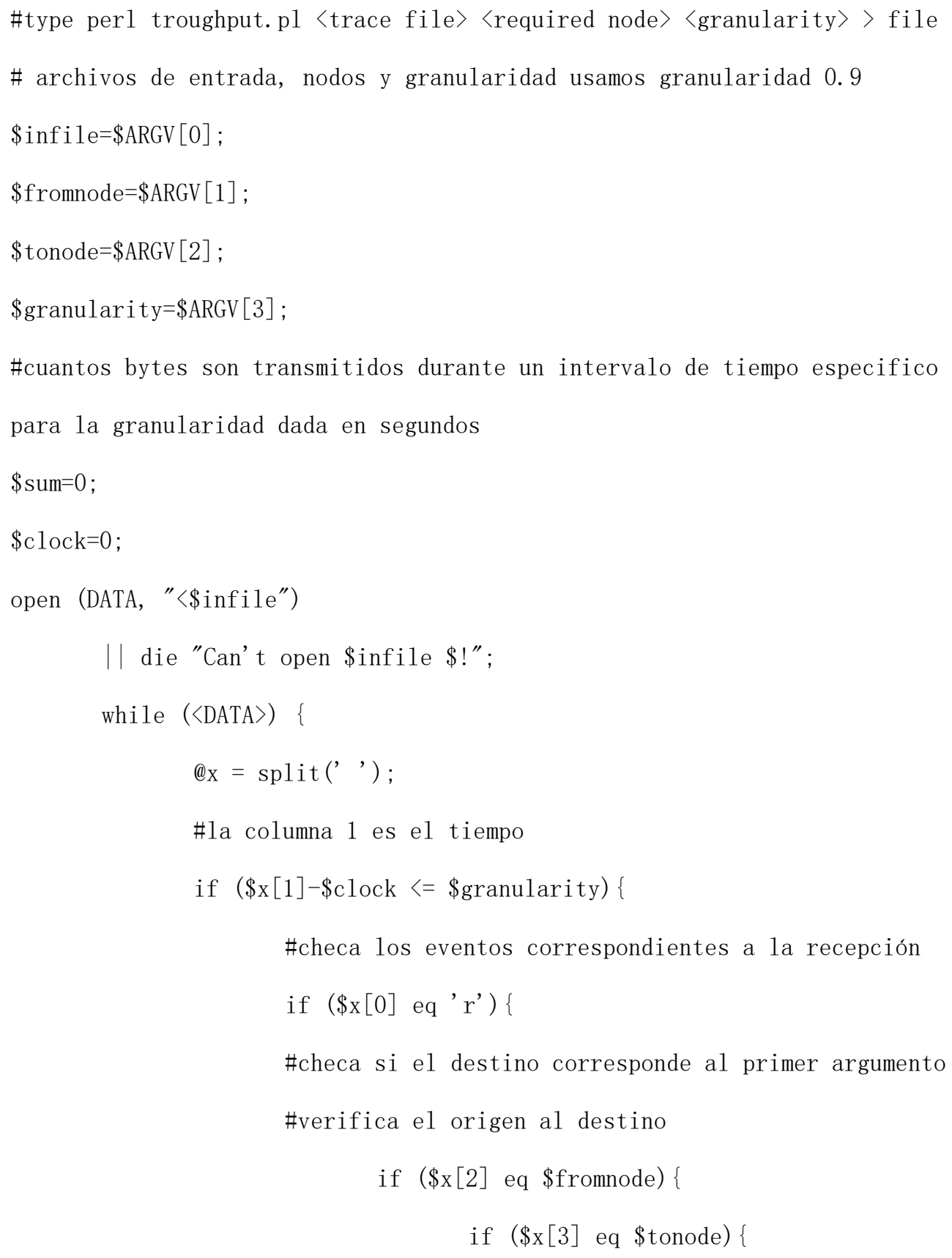


\#checa si los paquetes son del tipo CBR

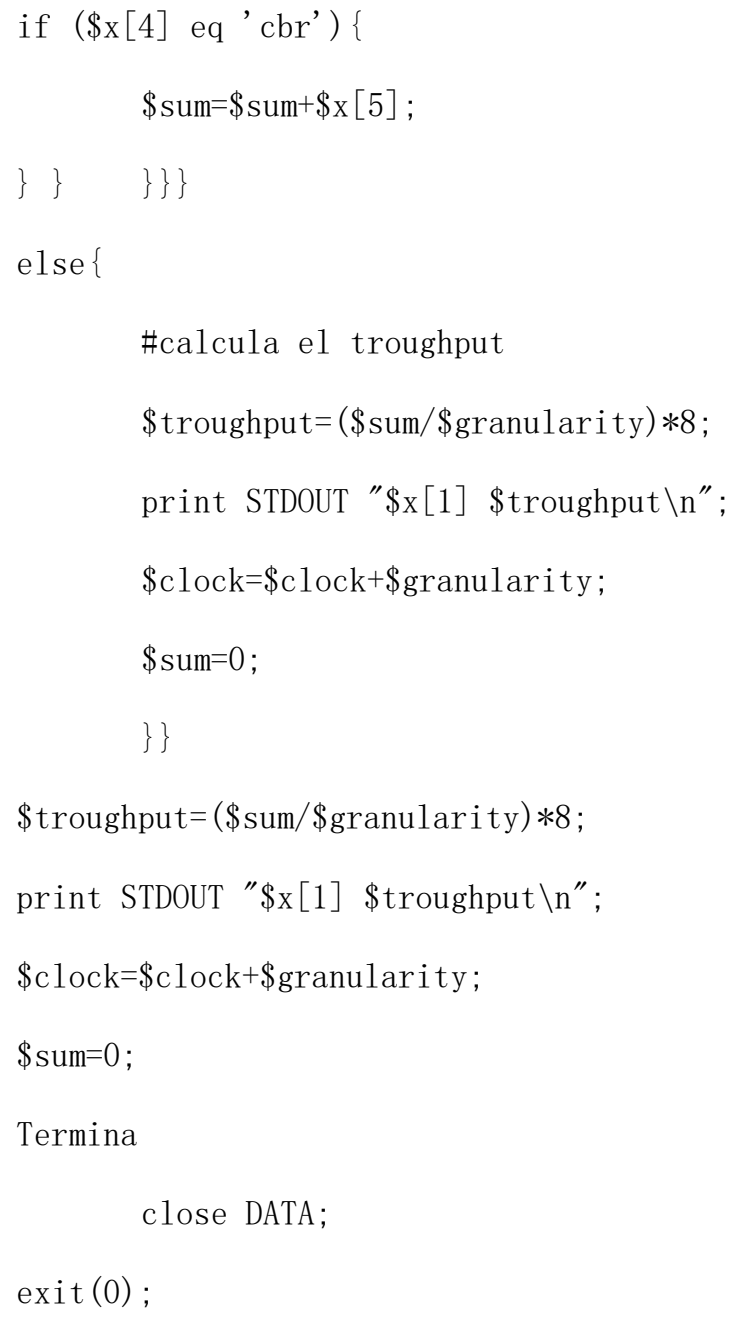




\section{ANEXO B. Programa para la simulación de US y UP en NS-2

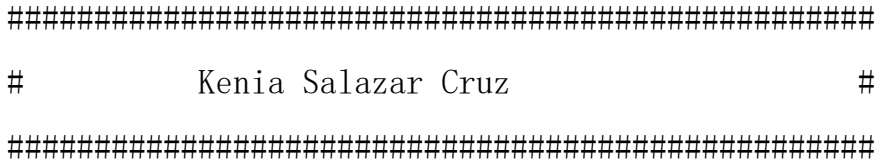




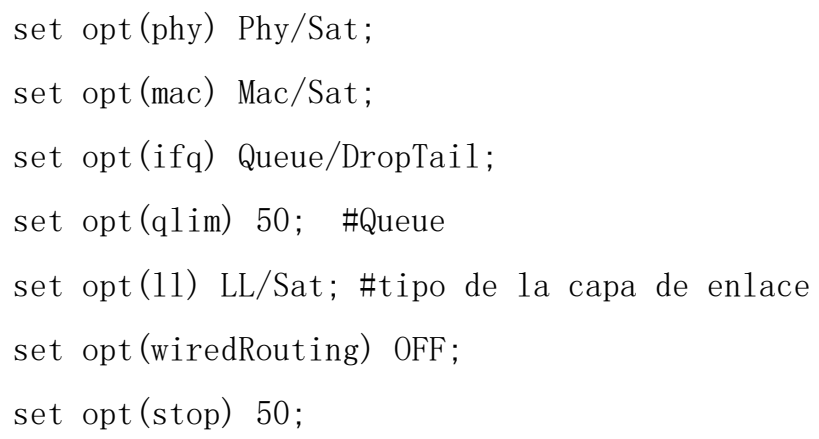




\section{\#\#\#\#\#\#\#\#\#\#\#\#\#\#\#\#\#\#\#\#\#\#\#\#\#\#\#\#\#\#\#\#\#\#\#\#\#\#\#\#\#\#\#\#\#\#\#\#\#\#\# \\ \# Se configura el nodo Satelite \# \\ \#La posición en grados \# \\ \#\#\#\#\#\#\#\#\#\#\#\#\#\#\#\#\#\#\#\#\#\#\#\#\#\#\#\#\#\#\#\#\#\#\#\#\#\#\#\#\#\#\#\#\#\#\#\#\#\#}

\$ns node-config - satNodeType geol

set $n(0) \quad[\$ n s$ node $]$

$\$ n(0)$ set-position -61

\#\#\#\#\#\#\#\#\#\#\#\#\#\#\#\#\#\#\#\#\#\#\#\#\#\#\#\#\#\#\#\#\#\#\#\#\#\#\#\#\#\#\#\#\#\#\#\#\#\#\#\#\#

\# Se configuran los nodos tipo terminal \#

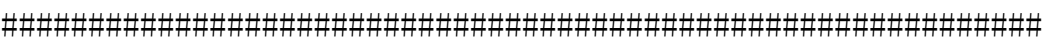

\$ns node-config -satNodeType terminal ।

$$
\begin{aligned}
& \text {-11Type \$opt (11) । } \\
& \text {-ifqType \$opt (ifq) । } \\
& \text {-ifqLen \$opt (qlim) । } \\
& \text {-macType \$opt (mac) । } \\
& \text {-phyType \$opt (phy) । } \\
& \text {-channelType \$opt (chan) । } \\
& \text {-downlinkBW \$opt (bw_down) । } \\
& \text {-wiredRouting \$opt (wiredRouting) }
\end{aligned}
$$

\#\#\#\#\#\#\#\#\#\#\#\#\#\#\#\#\#\#\#\# CREA LOS NODOS DE LAS ESTACIONES PRIMARIAS\#\#\#\#\#\#\#\#\#\#\#\#\#\#\#

set nodos_primarios [expr \$numero_de_usuarios_primarios * 2]; \#Número de nodos primarios $* 2($ Tx y $\mathrm{Rx})$

set y_start 1; \#Los nodos primarios comenzarán de 1

set y $\left[\operatorname{expr}\left\{\$ y \_s t a r t+\$\right.\right.$ nodos_primarios $\left.\}\right]$;

set prueba_nodos_P 0

\# Crea tantos nodos yo le diga en set nodos_cognitivos 
\# y los guarda en una lista prueba_nodos_P, con sus diferentes números

\# comenzando de $\$$ x_start

for $\{$ set i $\$$ y_start $\} \quad\{\$ i<\$$ y $\{$ incr $i\}\{$

set $n(\$ i) \quad[\$ n s$ node $]$

set prueba_nodos_P $\$$ i

lappend 1ista_nodos_primarios \$prueba_nodos_P

\}

\#Les asigna las posiciones a los nodos primarios

\#Posiciones iniciales

set lat 19. 361897

set lon -99.073823

for $\left\{\right.$ set i $\left.\$ y \_s t a r t\right\} \quad\{\$ i<\$ y\} \quad\{$ incr $i\}\{$

$\$ \mathrm{n}(\$ \mathrm{i})$ set-position [expr $\{\$ 1 \mathrm{lat}\}][\operatorname{expr}\{\$ 1 \mathrm{on}\}]$

\}

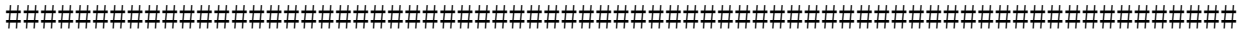

\# Va poniendo los parámetros alos US

set nodos_cognitivos [expr \$numero_de_usuarios_cognitivos * 2]; \#Número de nodos cognitivos $* 2$ ( Tx y $\mathrm{Rx})$

set x_start 200; \#Los nodos secundarios comenzaran de 100

\# Suma donde comienzan y los nodos para ver donde debe terminar

set $\mathrm{x}\left[\operatorname{expr}\left\{\$ \mathbf{x} \_\right.\right.$start $+\$$ nodos_cognitivos $\left.\}\right]$;

set prueba_nodos 0

\# Crea tantos nodos yo le diga en set nodos_cognitivos

\# y los guarda en una lista prueba_nodos, con sus diferentes números

\# comenzando de $\$$ x_start

for $\{$ set i $\$$ X_start $\} \quad\{\$ i<\$$ x $\}$ incr $i\}\{$

set $n(\$ i)$ [\$ns node]

set prueba_nodos $\$$ i

lappend 1ista_nodos \$prueba_nodos\} 
\# Les asigna las posiciones a los nodos COGNITIVOS

\#Posiciones iniciales

set lat 19

set 1 on -99

for $\{$ set i $\$$ X_start $\} \quad\{\$ i<\$ x\}$ incr $i\}\{$

$\$ \mathrm{n}(\$ \mathrm{i})$ set-position [expr $\{\$ 1 \mathrm{lat}\}][\operatorname{expr}\{\$ 1 \mathrm{on}\}]$

\}

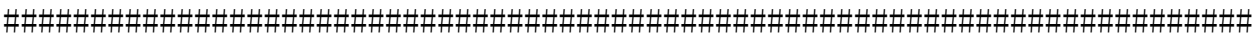

\# Se crea el enlace tierra-satelite: GSL (ground to satellite link)

\# En este primer caso son 2 nodos y se les da su posición

\# \$alt \$inc \$1on \$alpha \$plane // altitude, inclination, and longitude \#

\#Enlaces satelitales

\#\$ns add-is1 \$11 \$n1 \$n2 \$bw_up \$ifq \$q1im

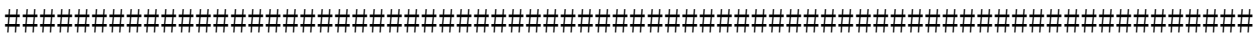

puts "\nEstaciones Primarias: \$numero_de_usuarios_primarios, Estaciones Secundarias: \$numero_de_usuarios_cognitivos"

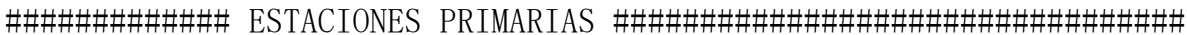

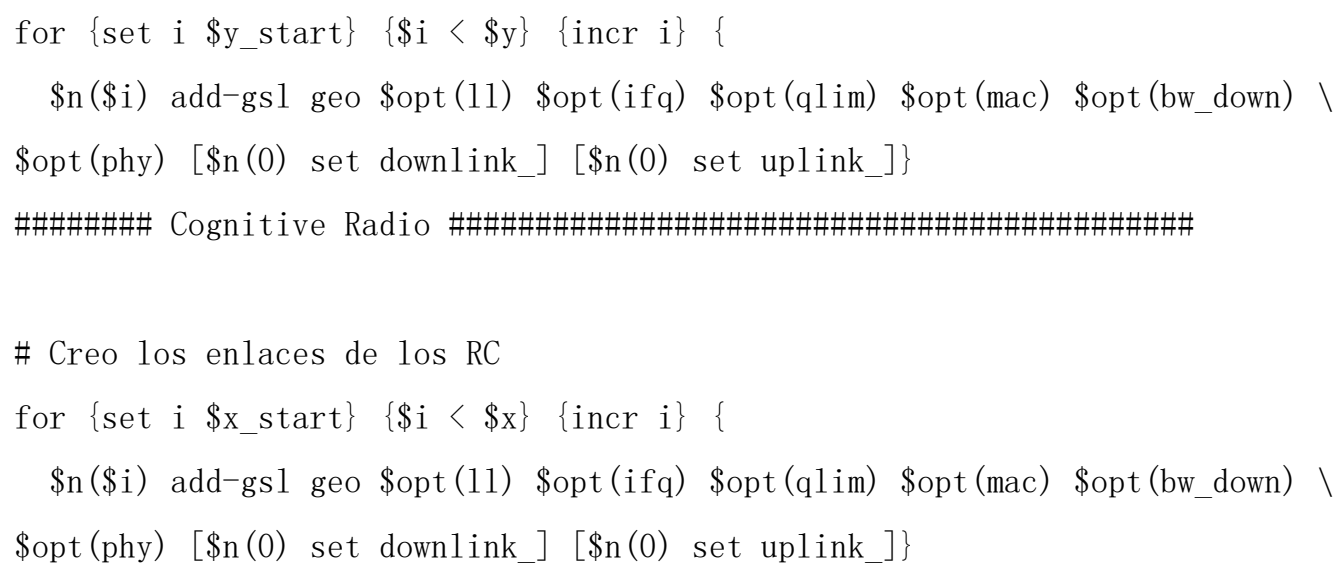




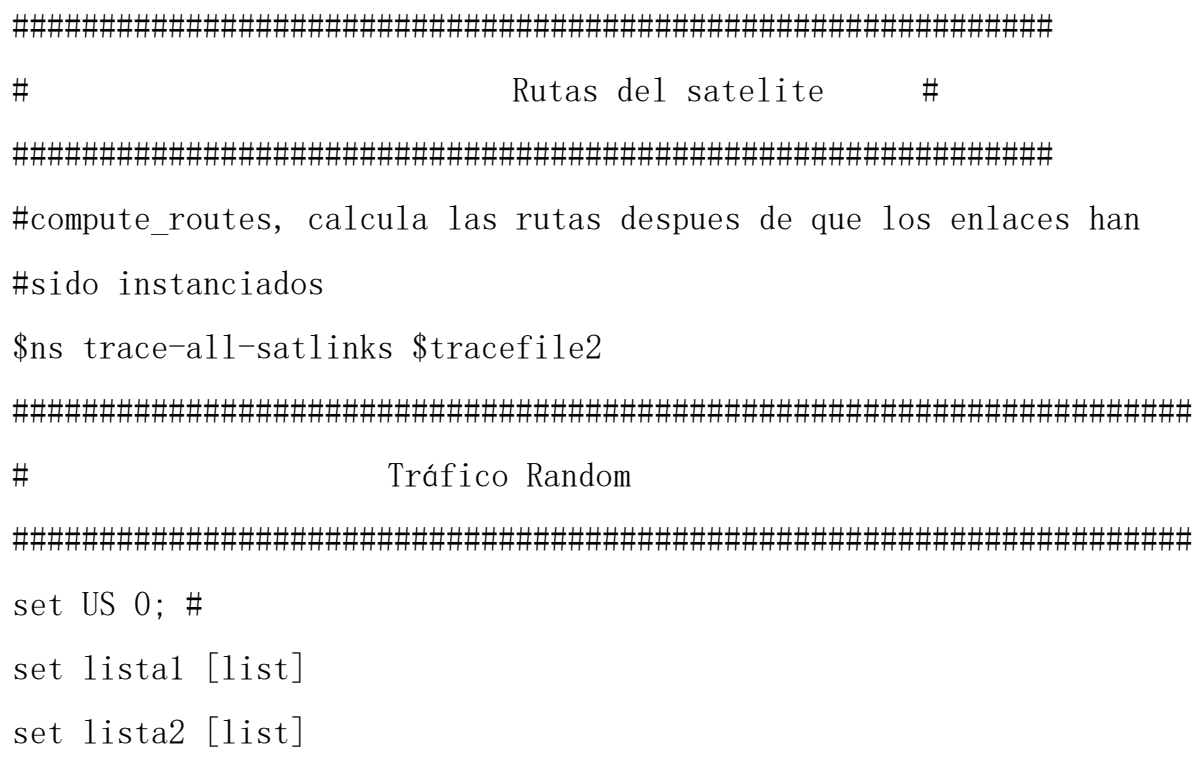




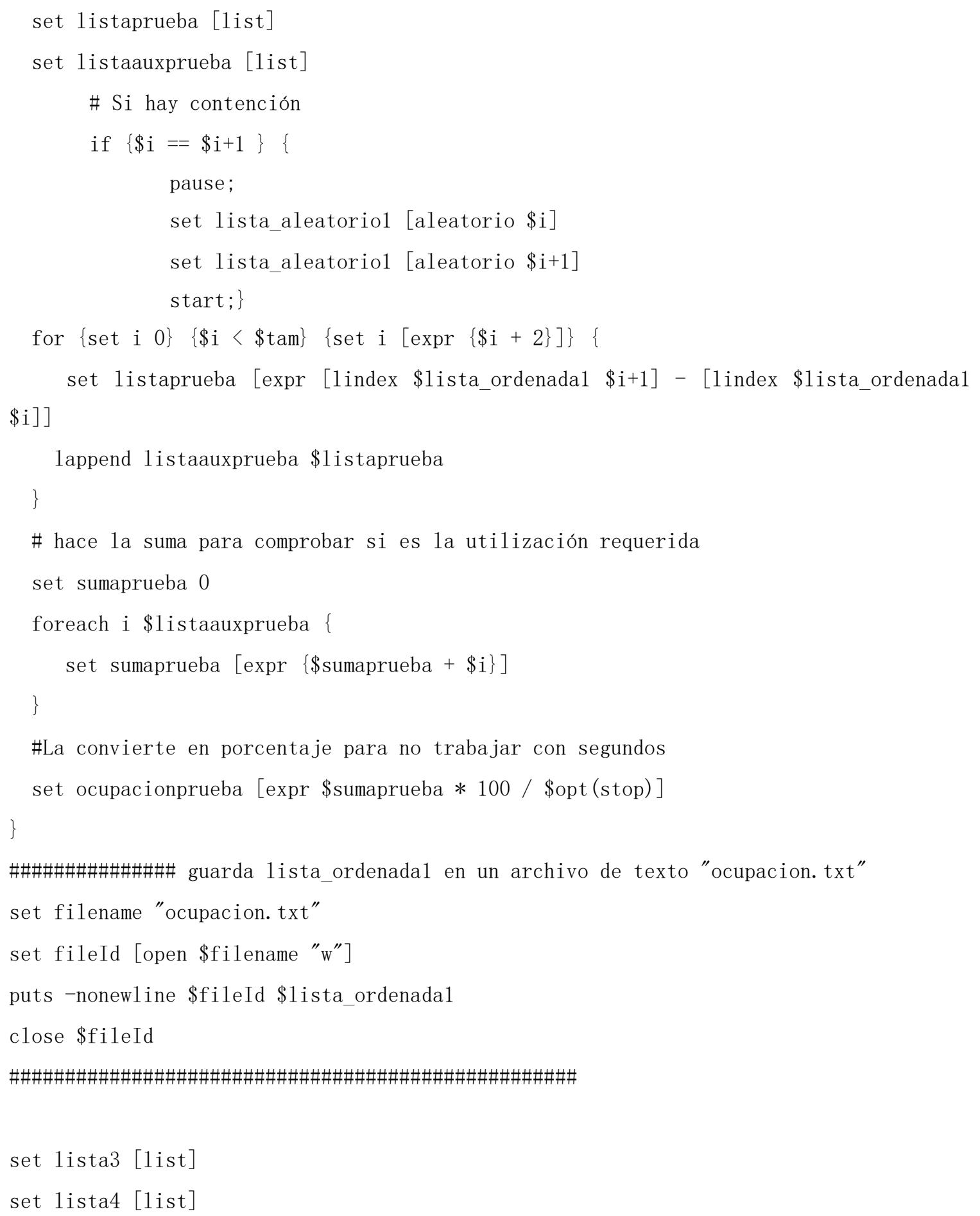


set 1 ista5 [1ist]

\#tomo cada dos números ------------------ se genera el trafico cbr

for $\{$ set $\mathrm{j} 0\} \quad\{\$ \mathrm{j}<[1$ length $\$ 1$ ista_nodos_primarios $]\} \quad\{$ set $\mathrm{j}[\operatorname{expr}\{\$ \mathrm{j}+2\}]\}\{$

if $\{[1$ index $\$ 1$ ista_nodos_primarios $\$ j]<[\operatorname{expr}\{\$ y-1\}]\} \quad\{$

set nodo_p_tx [1index \$1ista_nodos_primarios $\$ \mathrm{j}]$

set nodo_p_rx [1index $\$ 1$ ista_nodos_primarios $\$ j+1]$

set udp [new Agent/UDP]

\$ns attach-agent \$n(\$nodo_p_tx) \$udp

set cbr [new Application/Traffic/CBR]

$\$ c b r$ attach-agent \$udp

$\$ c b r$ set rate_ $1 \mathrm{Mb}$

$\$ c b r$ set packetSize_\$pak

set nul1 [new Agent/Nul1]

\$ns attach-agent \$n(\$nodo_p_rx) \$nul1

$\$$ ns connect $\$$ udp $\$$ null

\}

\#Transmite la estación primaria

\#Asegura un tiempo mínimo de transmisión

set tiempo_minimo_prim [expr \{[1index \$1ista_ordenada1 $\$ j+1]-[1$ index $\$ 1$ ista_orde nada1 $\$ j]\}]$

if $\{\$$ tiempo_minimo_prim $!=0\} \quad\{$

\$ns at [1index \$1ista_ordenada1 \$j] "\$cbr start"

$\$$ ns at [1index $\$ 1$ ista_ordenada1 $\$ j+1]$ "\$cbr stop"

\}

set d [expr [1index $\$ 1$ ista_ordenada1 $\$ \mathrm{j}+1]-[1$ index $\$ 1$ ista_ordenada1 $\$ \mathrm{j}]$ ]

lappend 1ista3 $\$ \mathrm{~d}$

\# en la lista4 se crea una copia de la lista_ordenada1 para poder modificarla

\$ns at [1index \$1ista_ordenada1 \$j] "\$cbr start"

$\$$ ns at [1index $\$ 1$ ista_ordenada1 $\$ j+1]$ "\$cbr stop" 
\}

\# if $\{[1$ index $\$ 1$ ista_ordenada1 $\$ j] !=[1$ index $\$ 1$ ista_ordenada $1 \$ j+1]\}\{$

lappend 1ista4 [1index $\$ 1$ ista_ordenada1 $\$ \mathrm{j}$ ]

lappend lista4 [1index \$1ista_ordenada1 $\$ \mathrm{j}+1$ ]

\#

if $\{\$ j==\$ j+1\} \quad\{$

pause;

set 1ista_aleatorio1 [aleatorio $\$ \mathrm{j}$ ]

set 1ista_aleatorio1 [aleatorio $\$ \mathrm{j}+1$ ]

start;\}

\}

\#imprime los segmentos en los que envia trafico el UP

puts "\nSegmentos de tráfico primario = \$1ista4 \n"

\# puts "número a sumar = \$1ista3"

set suma 0

foreach i $\$ 1$ ista3 \{

set suma $[\operatorname{expr}\{\$$ suma $+\$ i\}]$

\}

set ocupacion $[\operatorname{expr} \$$ suma $* 100 /$ opt (stop) $]$

puts "ocupacion estaciones primarias = \$ocupacion \% \n"

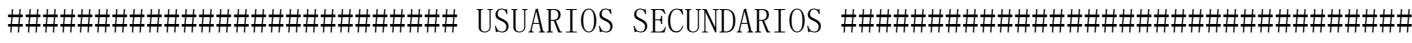

\#\#\#\#\#\#\#\#\#\#\#\#\#\#\#\#\#\#\#\#\#\#\#\#\#\#\#\#\#\#\#\#\#\#\#\#\#\#\#\#\#\#\#\#\#\#\#\#\#\#\#\#\#

\# Estaciones Secundarias \#

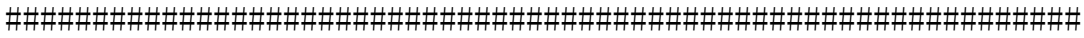

for $\{$ set i 0$\} \quad\{\$ i<[1$ length $\$ 1$ ista_nodos $]\} \quad\{$ set i $[\operatorname{expr}\{\$ i+2\}]\}\{$; \# Primer FOR for $\{$ set j 0$\} \quad\{\$ j<=[1$ length $\$ 1$ ista4 $]\} \quad\{$ set $j[\operatorname{expr}\{\$ j+2\}]\} \quad\{$; \#va de 0 a número de US*2, ej. 6

if $\{[$ lindex $\$ 1$ ista_nodos $\$ i]<[\operatorname{expr}\{\$ x-1\}]\} \quad\{$

set nodo_tx [1index $\$ 1$ ista_nodos $\$ i]$ 
set nodo_rx [1index $\$ 1$ ista_nodos $\$ i+1]$

\# puts "nodo_tx $=\$$ nodo_tx"

\# puts "nodo_rx $=\$$ nodo_rx"

set udp1 [new Agent/UDP]

\$ns attach-agent \$n (\$nodo_tx) \$udp1

set cbr1 [new Application/Traffic/CBR]

\$cbr1 attach-agent \$udp1

$\$$ cbr 1 set rate_ $1 \mathrm{Mb}$

$\$ c b r 1$ set packetSize_\$pak

set nu111 [new Agent/Nul1]

\$ns attach-agent \$n(\$nodo_rx) \$nul11

$\$$ ns connect $\$$ udp1 $\$$ null1

\}

if $\{\$$ US $<=3\} \quad\{$

if $\{\$$ US $==0\} \quad\{$

if $\{\$ j=0\} \quad\{$

\#Analiza el primer segmento, si el UP empieza en núm !=0; US empieza en 0

if $\{[$ lindex $\$ 1$ ista4 $\$ j] !=0\}\{$

\#Decide con cual US va a comenzar 1-MORAD0; 2-VERDE; o 3-AZUL

\# puts "\ntráfico enviado es MORADO de tx= [1index \$1ista_nodos $\$ i]$ a $r x=$

[1index $\$ 1$ ista_nodos $\$ i+1] "$

puts "se envía tráfico secundario de 0 a [1index \$1ista4 0] $\backslash \mathrm{n}^{\prime \prime}$

set tiempo_minimo_sec $[\operatorname{expr}\{[1$ index $\$ 1$ ista4 0$]\}-0]$

\# puts "tiempo_minimo_sec $=\$$ tiempo_minimo_sec"

set auxi $[\operatorname{expr}\{[1$ index $\$ 1$ ista4 0$]\}-0]$

\# \# agrega estas restas en la lista3

lappend 1ista5 \$auxi

\# puts "1ista $5=\$ 1$ ista $5 "$ 


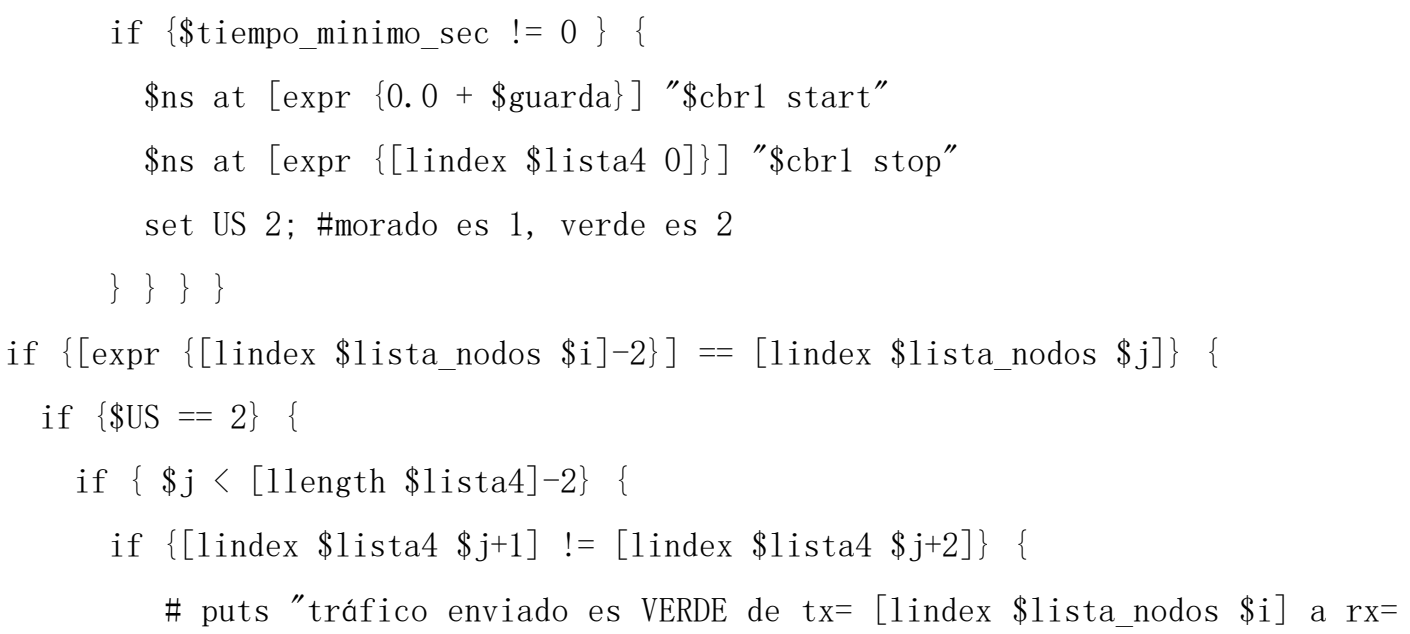
[1index $\$ 1$ ista_nodos $\$ i+1]$ " puts "se envía tráfico secundario de [lindex $\$ 1$ ista4 $\$ j+1]$ a [lindex $\$ 1$ ista4 $\$ j+2] \backslash n^{\prime \prime}$

set tiempo_minimo_sec $[\operatorname{expr}\{[\operatorname{expr}\{[1$ index $\$ 1$ ista4 $\$ \mathrm{j}+2]\}]-[\operatorname{expr}\{[1$ in$\operatorname{dex} \$ 1$ ista4 $\$ j+1]+\$$ guarda\} $]\}]$

\# puts "tiempo_minimo_sec $=$ \$tiempo_minimo_sec" set auxi [expr $\{[1$ index $\$ 1$ ista4 $\$ \mathrm{j}+2]\}-[$ lindex $\$ 1$ ista $4 \mathbf{j}+1]$ ]

\# \# agrega estas restas en la lista3

lappend 1ista5 \$auxi

\# puts " 1 ista $5=\$ 1$ ista5"

if $\{\$$ tiempo_minimo_sec $!=0\}\{$

\$ns at $[\operatorname{expr}\{[1$ index $\$ 1$ ista4 $\$ j+1]+\$$ guarda $\}]$ "\$cbr1 start"

\$ns at $[\operatorname{expr}\{[1$ index $\$ 1$ ista4 $\$ \mathrm{j}+2]\}]$ "\$cbr1 stop"

\} $\}\}\}\}$

if $\{[1$ index $\$ 1$ ista_nodos $\$ i]==[1$ index $\$ 1$ ista_nodos $[\operatorname{expr}\{[11$ ength $\$ 1$ ista_nodos $]$ $2\}]]\} \quad\{$

set US 3; \#morado es 1 , verde es 2

\} \}

set u [11ength $\$ 1$ ista5]

puts "1ongitud= $\$ \mathrm{u}^{\prime \prime}$ 


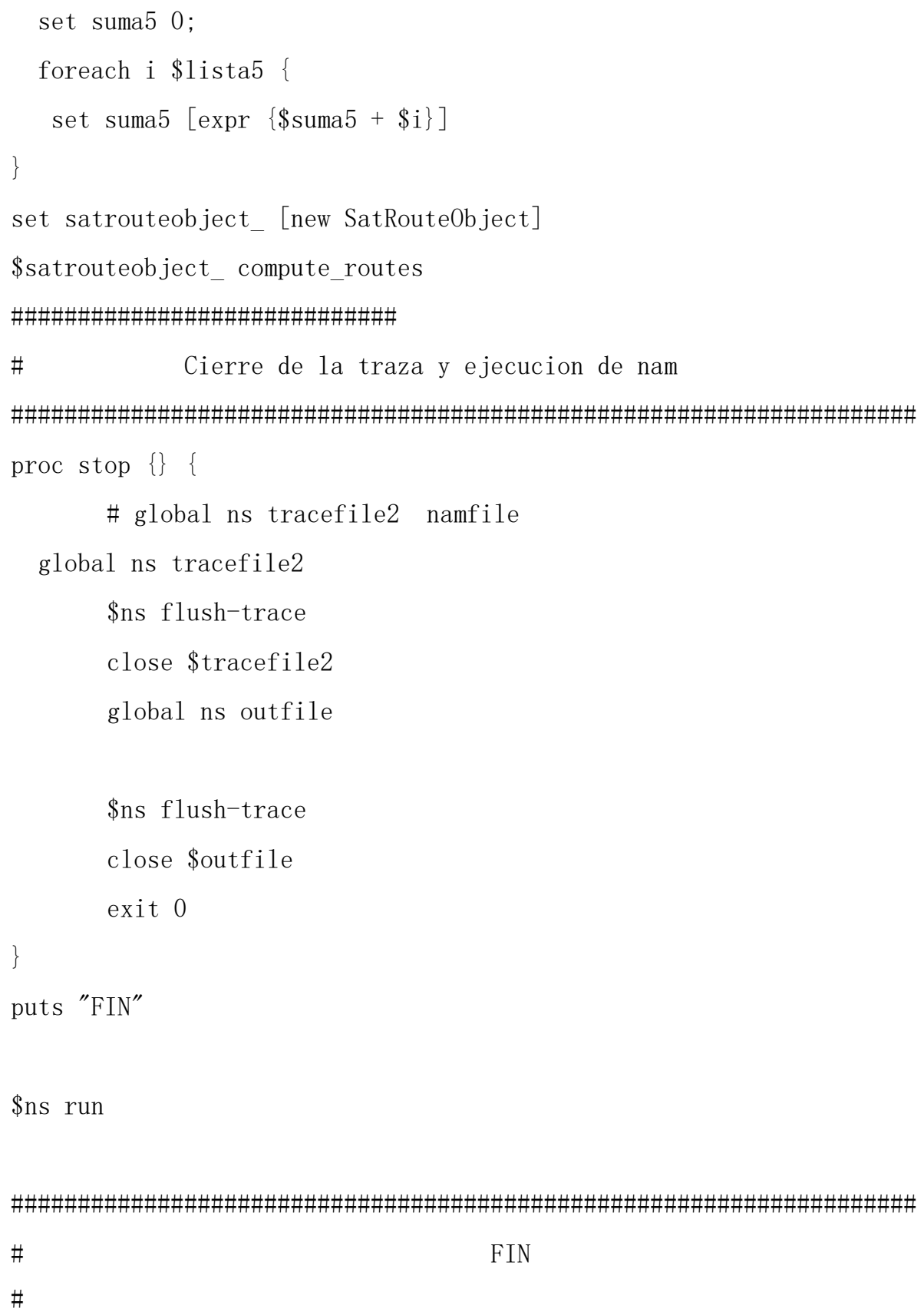



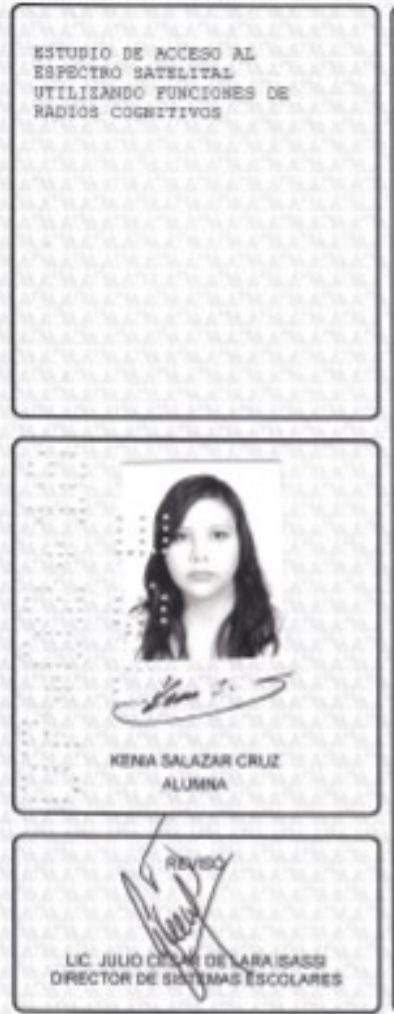

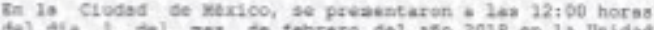
Wel dif i del nes de tebrero del affo 2018 en la Unidad

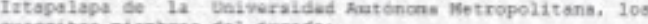
waserites nienbros del jurado:

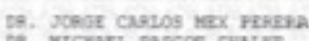

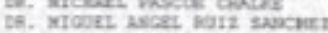

Aaje in Presidenela ded priners y ses esrbeter de

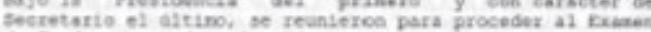
de crude euys dencainusien sparece al nargen, pare 14 cotenotice del quado de:

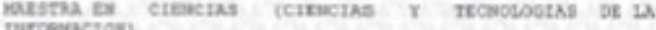
mircbeactosi

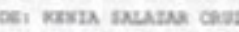

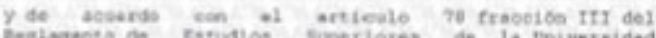

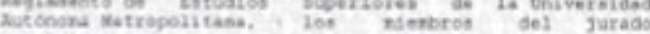
menotvierce

$$
\text { Aprobar }
$$

Nete sontinus, ol prenioente del jurads cominies a lo

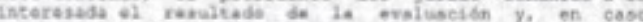
aprobatorio, is foe cooade is srotesta.

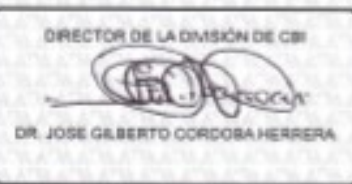

\section{Helde?}

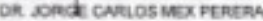

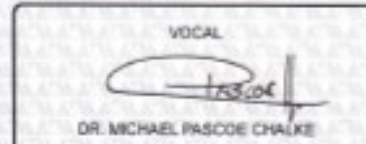

\section{SECRETARIO}

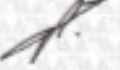

DR WOUEL ANGEL RUZ SUNCHEZ 